\title{
Study on the Retention of Large Mining Height and Small Coal Pillar under Thick and Hard Roof of Bayangaole Coal
}

\author{
Shankun Zhao $\mathbb{D}^{1,2}$ Jianping $\mathrm{Zuo} \mathbb{D}^{2},{ }^{2}$ Lei Liu, ${ }^{3}$ and Kaijun $\mathrm{Wu}^{2}$ \\ ${ }^{1}$ Mine Safety Technology Branch, China Coal Research Institute, Beijing 100013, China \\ ${ }^{2}$ School of Mechanics and Civil Engineering, China University of Mining and Technology (Beijing), Beijing 100083, China \\ ${ }^{3}$ School of Civil and Engineering, University of Monash, Melbourne, Australia
}

Correspondence should be addressed to Jianping Zuo; zjp@cumtb.edu.cn

Received 31 July 2020; Accepted 18 July 2021; Published 10 August 2021

Academic Editor: Robert Černý

Copyright ( $) 2021$ Shankun Zhao et al. This is an open access article distributed under the Creative Commons Attribution License, which permits unrestricted use, distribution, and reproduction in any medium, provided the original work is properly cited.

The coal pillar stress distribution at the 311102 working face in the Bayangaole Mine is analyzed and revealed. In addition, borehole stressmeter, PASSAT monitoring system, and numerical modelling are fully utilized. Based on the patterns of acoustic wave velocity distribution, it is discovered that the impact created by mining activity can expand into the working face around $40 \mathrm{~m}$, where the peak stress concentration is found about $15 \mathrm{~m}$ ahead. According to borehole stressmeter readings, mildly impacted, ordinarily impacted, and severely impacted zones are distinguished. The equilibrium theory and corresponding calculation indicated that the coal body in front of the working face has a plastic zone width of $4.96 \mathrm{~m}$. The stress-displacement analysis based on numerical simulation showed that the relationship between peak vertical stress and pillar width is unimodal and bimodal. Specifically, both 5 and $10 \mathrm{~m}$ wide pillars showed a unimodal stress-width correlation and the peak vertical stresses are all located at the pillar center, whereas $15 \mathrm{~m}$ wide pillar has a bimodal stress-width relationship. In comparison, $10 \mathrm{~m}$ wide pillar holds the maximum in-situ stress. In consideration of site conditions and economic influences, $6 \mathrm{~m}$ wide coal strip coal pillar is designed at the working face 311102 . As a result, stopping was successfully completed, and remarkable economic benefits were achieved.

\section{Introduction}

In China, coal is the major component of nonrenewable energy resources. Optimizing recovery rate and mining safety is of great significance in both China's energy security system establishment and sustainable development strategy implementation. In fact, China has abundant reserves of thick coal seam, where thick coal seam mines make up $41 \%$ of the total coal mines. And, the reserves of thick coal mines, which are currently in production, accounted for $45 \%$ of the total coal reserves in China. Many mining methods were developed for excavation of extremely thick coal seams based on various geological conditions. However, it is still common that most coal mines adopted relatively large pillars for maintaining the preparation roadway, and it does waste a substantial amount of coal resources. Therefore, the research for nonpillar excavation becomes the key technology for the sake of safety and effectiveness.
The traditional design width of the strip coal pillar is inbetween 10 and $40 \mathrm{~m}$ with coal loss rate ranging from $10 \%$ to $30 \%$, and this design approach mainly focuses on ventilation, transportation, and safety. When its roadway stability is impacted by stopping activities, the stress concentration always causes maintaining difficulties. Therefore, some mining experts proposed nonpillar (small coal pillar) goafside entrydriving method, which only leaves 3-7 m thick strip coal pillar on the gob side, to ensure the roadway stability and improve recovery rate after the overburden is stabilized. Goaf-side entrydriving is normally started after several months or if the working face has already advanced to a certain distance in the upper panel. The excavation advances along with the goaf side and only leaves a relatively thin coal pillar to isolate and protect the roadway. According to the mine pressure distribution, goaf-side entrydriving is normally longitudinally located in the stable bearing pressure zone, and transversally located in the coal wall plastic zone. Therefore, gob-side entrydriving can not only improve 
the recovery rate sufficiently but also reduce both maintaining cost and workload as the excavation is conducted in the plastic zone, where the confining pressure is relatively low.

In 1911, the first empirical formula for coal pillar strength was presented by Bunting via testing the strength of anthracite blocks of different sizes and shapes [1]. Then, Gaddy [2] presented the relation between the strength of test blocks decreasing and the size increasing, and simultaneously the calculation formula for coal pillar strength with consideration of laboratory test values after testing the strength of coals with different sizes was also proposed. Iannacchione and Mark [3] evaluated several theories of coal pillar strength after testing the actual coal pillar stress. Based on the investigation and analysis of a large number of unstable coal pillars in South Africa, Salamon et al. [4, 5] summarized that most successful coal pillar designs adopted the inversion method. Chen et al. [6] studied the influence of confining pressure and confining pressure unloading rate on crack growth characteristics. At the same time, after analyzing 23 unstable coal pillars and 20 stable pillars in India, a strength formula suitable for coal pillars with different ratios of width to height was presented by Loui and Sheorey [7].

In recent years, China's coal mining technicians conducted a large number of research works on the controlling techniques of country-rock under the direct influence of stopping activities. Li et al. [8] collaborated six classical coal mining cases from the East to the West of China, and the key factors that induced deformative failure on thin coal pillars were analyzed and collaborated. By applying numerical analysis, Bai et al. [9] investigated how coal pillar width, coal seam mechanical characteristics, and rock bolt supporting strength affects both country-rock deformation and coal pillar strength during the gob-side entrydriving. Sun et al. [10] came up with a novel method for predicting movement and damage of inner burden caused by coal mining. Based on FLAC3D numerical analyses and engineering site experiments, Zheng et al. [11] obtained a series of stress distribution behaviors in coal pillars during the entire stopping process, and specifically investigated the influences, which are created by pillar width variation, on both stopping pillar and the evolution of coal rib stress; Zhang et al. [12] further researched and ascertained the width of coal pillars based on five aspects, which are the distribution of upper goaf rib-bearing stress, upper goaf stress field distribution, upper goaf displacement field distribution, the correlations between roadway country-rock and pillar width, as well as the equilibrium theory of small pillar width. Based on macro and micro failure experiments and numerical analysis, Zuo et al.[13] established the theoretical model of gradient failure of the surrounding rock mass of deep roadway, and presented the relationship between relative stress gradient and the average tangential stress level provided by the surrounding rock mass.

Wei [14] measured the deformation and stress distribution of room and pillar-mined coal pillars. He et al. [15] established the global constitutive double yield and strainsoftening model and studied the abutment pressure and plastic failure range of coal seams with different thickness and pillar width. Frith and Reed [16] explore the reasons why empirically derived coal pillar strength equations tend to be problem-specific and should be considered as providing no more than a pillar strength "index." In order to reveal the mechanism of coal pillar impact from the perspective of energy evolution, Xue et al. [17] conducted an experiment on the bursting liability of coal samples during the third period of tunneling in no. 6 roadway of a certain mine. Li [18] studied the influence of coal pillar size on stress direction, plastic zone distribution, and roof stability of deep mining roadway. In addition, the study reveals the mechanical nature of the influence of coal pillar size on the shape of surrounding rock plastic zone in deep roadway. Based on the downhole pressure control theory, Shi et al. [19] expound the distribution characteristics of supporting stress in coal seam before work and its damage to coal seam. And, Chen et al. [20] studied the deformation of strip coal pillars under longterm stress by means of a borehole pressure gauge and displacement monitor. Chen et al. [21] proposed to use the natural strain described in Hooke's law to establish the constitutive relation of coal and rock mass so as to accurately simulate the deformation of coal and rock mass.

In general, a strip coal pillar always has certain strength and is hence capable of supporting overlying strata in the earlier stages. However, some coal pillars which were once stable may become unstable and collapse, leading to surface subsidence. American coal mines have suffered surface collapse due to coal pillar instability more than 100 years after construction. An abandoned mine in Scotland caused surface subsidence 118 years after it had been scrapped. The Wieliczka salt mine in Poland suddenly exhibited surface subsidence after 140 years of mining, resulting in the destruction of all surface buildings. And most unstable coal pillars in South Africa have suffered from surface subsidence after many years of mining. These facts indicate that although the deformation of pillars becomes stable in the short term, they may deteriorate after a long period of damage accumulation, leading to unstable failure in the coal pillar or seam roof. Therefore, the long-term bearing capacity of the strip coal pillar is a key factor in determining whether or not the safety of surface structures (buildings) in the mining area could be maintained for a long period of time.

In this study, the strip mining of Shandong Daizhuang Coal Mine was used as the experimental site to measure the bearing capacity of a strip coal pillar at different depths of a pillar during or after mining. In this way, the complicated effects of various factors on the strength and bearing capacity of the coal pillar are skillfully avoided. In addition, the study is also attempted to determine the actual bearing capacity of the strip coal pillar at different pillar depths. The results are of practical significance for the optimal design of strip coal pillars for long-term stability.

Bayangaole mine is in Wushen county, Ordos city, Inner Mongolia. Coal pillar supporting technique was adopted, and its ventilation roadway is the auxiliary haulage gate of the upper working face. As the roadway is doubly impacted by mining activities, palpable floor heaves, country-rock deformation, and even local rock burst were triggered during the stopping process. Zuo et al. [22] analyzed strength and 
deformation and failure characteristics of samples under different combination modes, and discussed the influence of different combination modes on bursting liability and the interaction between coal and rock. Regarding coal pillar width design, theoretical analysis, numerical simulation, and engineering analogy are fully utilized in order to reveal the coal pillar mechanical characteristics, failure mode, overburden movement behaviors, and abutment pressure distribution. Zuo et al. [23] studied the influence of temperature, stress, composition, and other factors on rock permeability, and analyzed the changing law of sandstone samples under the changing rate of confining pressure and pore pressure after high temperature treatment. Meanwhile, this research is significant to the recovery rate improvement; roadway supporting optimization; geological hazard prevention; especially for rock burst; economic benefit improvement; and safety assurance. Sun et al. [24] studied the dynamic fracturing process of coal seam hard rock coal pillar.

\section{Bayangaole Mine Geological Conditions and Stress Distribution}

Bayangaole mine is located $3 \mathrm{~km}$ to the northeast of Ulan Tolgoi, Wushen county, Ordos city, Inner Mongolia. This mine has a regular polygon planar configuration, in which the East-West length is $10.64 \mathrm{~km}$, North-South width is $7.79 \mathrm{~km}$, and the area is $65.2734 \mathrm{~km}^{2}$.

Bayangaole mine is in the southeast of Dongsheng coal field, and most coal seams are deeply buried with burial depth greater than $660 \mathrm{~m}$. Three major seams have been discovered in this mine, where 2-1 and 2-2 coal seams are partially extractable, and 3-1 coal seam is fully extractable. Based on the existing geological investigations, 3-1 coal seam only interacts with simple geological structures, and rock parting was barely found. The roof consists of silty/sandy mudstone with some minor siltstone and medium to small grained sandstone, whereas the floor is mainly constituted of sandy mudstone.

2.1. General Situation of Working Face 311102. Working face 311102 is the second face of the $11^{\text {th }}$ panel zone in 3-1 coal seam at Bayangaole mine, with a trend length of $3578 \mathrm{~m}$, a dip length of $260 \mathrm{~m}$, an area of $930280 \mathrm{~m}^{2}$, and a burial depth of 610-629 m. Figure 1 illustrates the surroundings of this working face, where the goaf area caused by the 31110 working face is on the east side, the unexcavated working face 311103 is on the west side, whereas the water source protecting the pillar of coal and the 3-1coal auxiliary roadway are on the north and south side, respectively. The average coal seam thickness of this working face is $5.42 \mathrm{~m}$ and the coal seam has an average dip angle of 1.5 degrees.

Figure 2 shows the bore-log profile of coal seam 3-1, where the borehole directly passed through the coal panel. The immediate roof in this coal seam is sandy mudstone with a thickness variation of $0.98-5.97 \mathrm{~m}$, dark grey in color, and contains phytolite pieces and sliding surfaces with shale-like fractures. The main roof is small grained sandstone with a

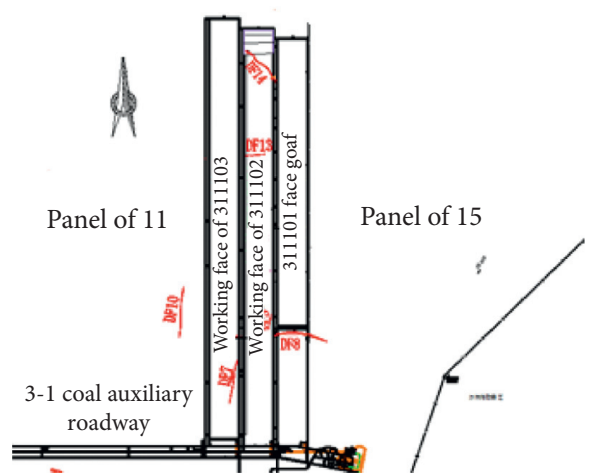

FIGURE 1: Schematic diagram of four-neighborhood relationships on working face of 311102 .

thickness variation of $9.9-36.83 \mathrm{~m}$, pile grey in color, interbedded with thin calcareous sandstone. Moreover, it has medium-high hardness. The main floor is mediumgrained sandstone, $8.45 \mathrm{~m}$ thick, grey to white in color with medium harness. The physical-mechanical parameters of the rocks mentioned above are all listed in Table 1.

2.2. Ground Stress Characteristics. In-situ stress is one of the most significant parameters that are required for the study on coal pillar and roadway stability. Overcorying stress relief method was adopted for in-situ stress testing, and a site testing approach, which utilizes a refined Hollow Inclusion Strain Gauge, was applied. The refined Hollow Inclusion Strain Gauge has developed a new collection board that provides the functions of simultaneous collection, collection without external power supply, and automatic drifting correction. In addition, temperature compensation circuit was also designed and developed. ADuC847 microprocessor was integrated into this circuit with $5 \mathrm{~V}$ battery power supply; voltage regulation chip was used instead of the traditional voltage regulation model and each channel has an individual analog switch. The application of simultaneous collection with temperature compensation technology can ensure the signal integrity. This circuit has 16 signal input channels, in which 1-12 are the strain signal channels, 13-14 are the temperature compensation channels, and 15-16 are the signal distortion compensation channels. The temperature compensation algorithm built in this refined Hollow Inclusion Strain Gauge can reach up to $15 \%$ correction for measured data, and it only has $8 \%$ maximum error band with theoretical data.

Testing locations are determined based on following principles. A representative area of formation; In a complete or as complete rock mass as possible, it is generally required to stay away from faults and avoid rock fracture zones and fault development zones. Zuo et al. [25] used LSDYNA numerical simulation software to analyze and compare the variation trend of the mises stress evolution and effective stress strain at the observation points around the hole under three layout modes in Bayangaole coal mine. People should stay away from or as far as possible from larger excavated bodies, such as large goaf, large adit 


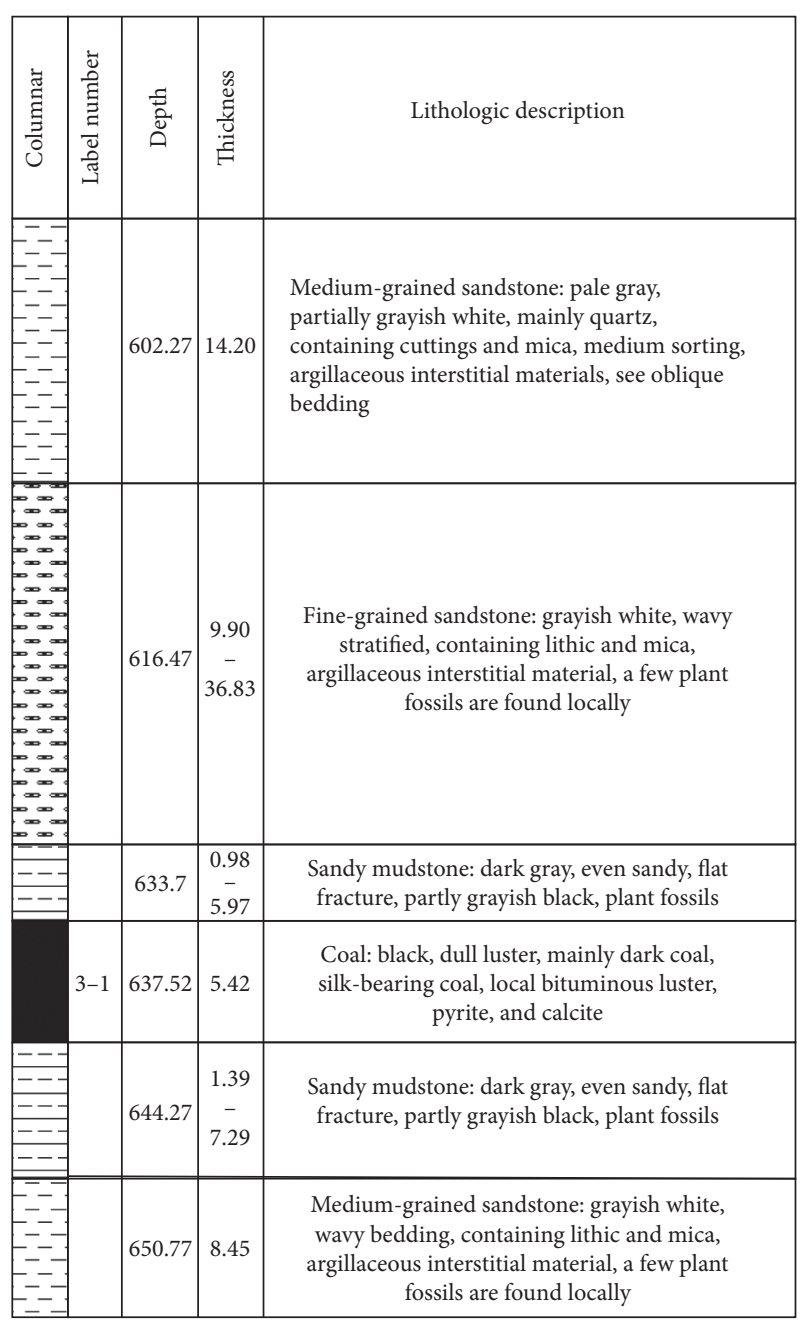

FIGURE 2: 3-1 coal roof and floor lithology column chart.

chamber, etc. Liu et al. [26] carried out multi-scale hierarchical analysis of rock mass and predicted its mechanical and hydraulic characteristics. Yu et al. [27] conducted tests on mechanical properties of sandstone and coal bolts under conventional triaxial compression at different angles. Wu et al. conducted experimental and theoretical research on the mechanical properties of coal rock bolt (RCB) composite system [28]. The stress concentration areas such as bend, fork, bend and top of roadway and stope should be avoided, and the stress measuring point must be located in the stress area of the original rock-the area where the original stress state is not disturbed by the engineering. In order to study the variation of stress state with depth, measurements should be made at three or more levels as far as possible. In addition to the above principles, the actual conditions on-site should also be considered. According to the above principles, combined with detailed scene investigation, it is decided to arrange three geostress measuring points in Bayangaole mine. The relevant parameters of each measuring point are shown in Table 2, and the positions of each measuring point are shown in Figure 3.

Most of the stress relief curves obtained from the three measuring points in Bayangaole mine change regularly, indicating that the working state of most strain gauges is normal. Stress relief curves of the three measuring points are shown in Figure 4.

According to the tested strain readings, rock mechanical parameters, and the bore-hole geometric parameters, the principal in-situ stresses with their magnitude and direction are analyzed and calculated. The in-situ stress measurement results of Bayangaole mine are shown in Table 3.

Table 3 shows the testing results of in-situ stresses at three locations in Bayangaole mine, and the characteristics of in-situ stress field are discovered. The major principal stress is almost in a horizontal direction, and the ratio of maximum principal stress to its gravitational stress is $1.43-1.89$ with an average value of 1.63 . It is indicated that the in-situ stress filed in Bayangaole mine is dominated by its horizontal tectonic stress. Vertical stress is found to be equal to or slightly greater than the overburden weight. The average values of both major principal stresses and vertical stress are found to be almost directly proportional to the burial depth. As a result, the average values of $\sigma_{h \max }=25.76 \mathrm{MPa}, \sigma_{h \text { min }}=18.1 \mathrm{MPa}$, and $\sigma_{v}=15.74 \mathrm{MPa}$ are used for numerical simulation purposes.

\section{Monitoring the Stress Distribution of Mining Coal Pillar in Working Face 311102}

During the mining, a series of ore pressure shows up in the working face 311102. In particular, serious floor heave and slab appear in the advance range of $200 \mathrm{~m}$ in the return air roadway of 02 working face. After the working face advanced over $200 \mathrm{~m}$, serious floor heaving in the auxiliary haulage gate was also triggered by stopping. Hence, the mining stress in 02 working face was closely monitored for further pillar design purposes.

3.1. Wave Velocity Field of Coal Body in Pillar. Due to the stress field complexity and variation in coal pillar, the distribution of sonic wave velocity was tested as the stress detector can only acquire the point value. PASAT-M portable microseismic detecting technique as a geophysical method is designed to detect the structure of underground medium. Both sonic wave velocity distribution and corresponding elastic parameters were also obtained based on the analysis of seismic wave characteristics, which were acquired by PASAT-M. For the prevention of severe mining disasters, PASAT-M is used to monitor the failure motion in countryrock during excavation, and the PASAT-M testing system is sketched out in Figure 5(a).

In the case of seismic travel time imaging, it is assumed that seismic waves propagate in the medium inside the detection area in the form of rays, as shown in Figure 5(b). For image reconstruction of velocity field, common methods include backprojection (BPT), algebraic reconstruction (ART), joint iterative reconstruction (SIRT), conjugate gradient least square method, etc. SIRT was first proposed by Gilbert. Its formula is 
TABLE 1: Table of physical and mechanical parameters of coal strata.

\begin{tabular}{|c|c|c|c|c|c|c|c|}
\hline Coal bed name & $\begin{array}{l}\text { Thickness } \\
(\mathrm{m})\end{array}$ & $\begin{array}{l}\text { Bulk modulus } \\
\qquad(\mathrm{Pa})\end{array}$ & $\begin{array}{l}\text { Shear modulus } \\
\qquad(\mathrm{Pa})\end{array}$ & $\begin{array}{l}\text { Angle of internal } \\
\text { friction }\left(^{\circ}\right)\end{array}$ & $\begin{array}{l}\text { Cohesion } \\
(\mathrm{Pa})\end{array}$ & $\begin{array}{l}\text { Tensile strength } \\
(\mathrm{Pa})\end{array}$ & $\begin{array}{l}\text { Density } \\
\left(\mathrm{kg} / \mathrm{m}^{3}\right)\end{array}$ \\
\hline Siltstone & 13 & $6.03 e 9$ & $5.30 e 9$ & 28.08 & $1.06 e 7$ & $2.07 e 6$ & 2516 \\
\hline $\begin{array}{l}\text { Medium } \\
\text { sandstone }\end{array}$ & 22 & $2.26 e 10$ & $1.91 e 10$ & 37.08 & $6.20 e 6$ & $2.48 e 6$ & 2304 \\
\hline Sandy mudstone & 3 & $1.89 e 10$ & $9.73 e 9$ & 31.46 & $1.02 e 7$ & $1.11 e 6$ & 2503 \\
\hline Coal & 5 & $1.20 e 9$ & $8.60 e 8$ & 27 & $8.00 e 6$ & $1.85 e 6$ & 1400 \\
\hline Sandy mudstone & 4 & $1.89 e 10$ & $9.73 e 9$ & 31.46 & $1.02 e 7$ & $1.11 e 6$ & 2503 \\
\hline $\begin{array}{l}\text { Medium } \\
\text { sandstone }\end{array}$ & 8 & $2.73 e 9$ & $2.31 e 9$ & 32.54 & $8.00 e 6$ & $1.17 e 6$ & 2108 \\
\hline Siltstone & 18 & $6.03 e 9$ & $5.30 e 9$ & 28.08 & $1.06 e 7$ & $2.07 e 6$ & 2516 \\
\hline
\end{tabular}

TABLE 2: Borehole parameters table at measuring point.

\begin{tabular}{lcccc}
\hline Dot & Location & Elevation $(\mathrm{m})$ & Depth $(\mathrm{m})$ & Hole depth $(\mathrm{m})$ \\
\hline 1 & $3-1$ high fructose 6 conduction point of coal return ventilation roadway & 650 & 620 & 8 \\
2 & Guide point of S4 in the main channel 311103 & 651 & 620 & 8 \\
3 & Guide point J42 of the auxiliary channel on the 311102 working face & 646 & 636 & 8 \\
\hline
\end{tabular}

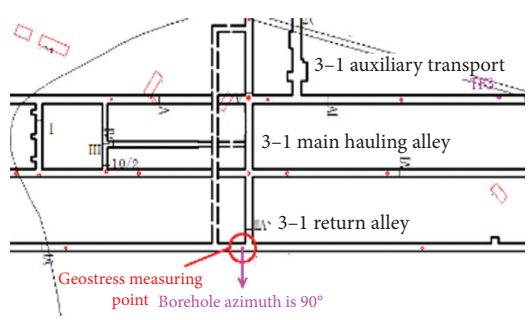

(a)

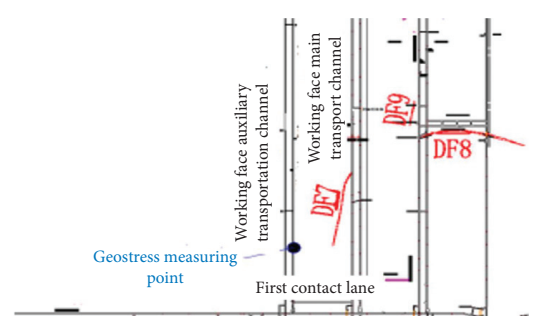

(b)

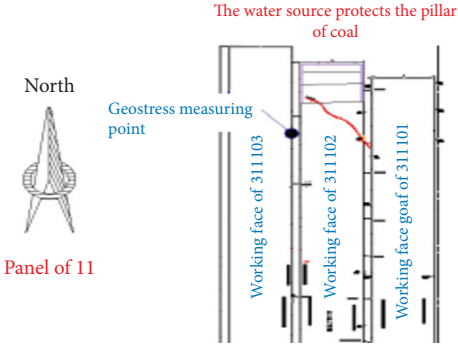

(c)

Figure 3: Schematic diagram of ground stress measuring point layout. (a) Point 1. (b) Point 2. (c) Point 3.

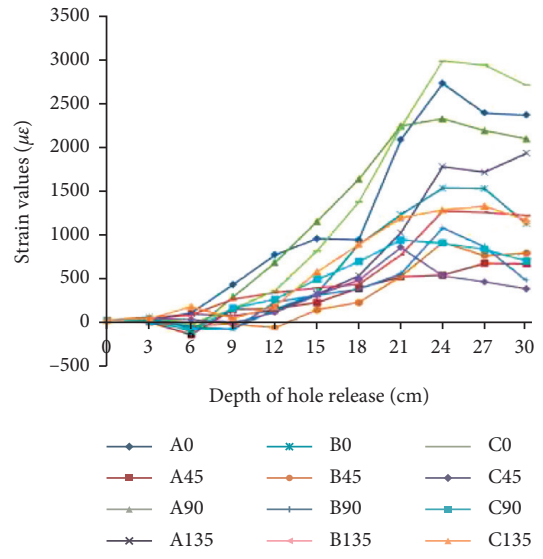

(a)

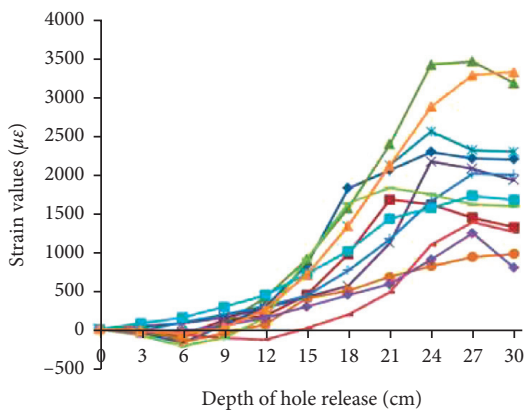

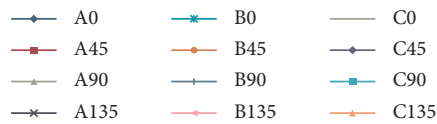

(b)

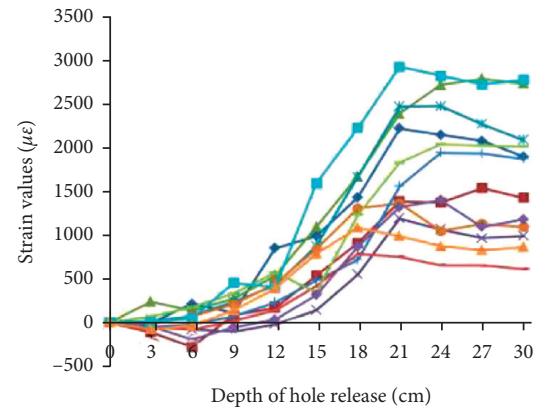

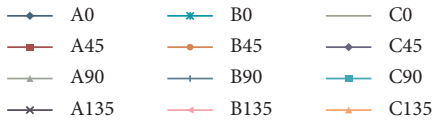

(c)

Figure 4: Stress relief curve at measuring point. (a) $1 \#$ measuring point. (b) 2\# measuring point. (c) $3 \#$ measuring point. 
TABLE 3: Calculation results of principal stress at each measuring point of Bayangaol mine.

\begin{tabular}{|c|c|c|c|c|c|c|c|c|c|c|}
\hline \multirow[b]{2}{*}{ Point } & \multirow{2}{*}{$\begin{array}{l}\text { Depth } \\
(\mathrm{m})\end{array}$} & \multicolumn{3}{|c|}{ Maximum principal stress $\left(\sigma_{\max }\right)$} & \multicolumn{3}{|c|}{ Intermediate principal stress $\left(\sigma_{\text {mid }}\right)$} & \multicolumn{3}{|c|}{ Minimum principal stress $\left(\sigma_{\min }\right)$} \\
\hline & & $\begin{array}{c}\text { Numerical } \\
(\mathrm{MPa})\end{array}$ & $\begin{array}{c}\text { Direction } \\
\left({ }^{\circ}\right)\end{array}$ & $\begin{array}{c}\text { Dip angle } \\
\left({ }^{\circ}\right)\end{array}$ & $\begin{array}{c}\text { Numerical } \\
(\mathrm{MPa})\end{array}$ & $\begin{array}{c}\text { Direction } \\
\left({ }^{\circ}\right)\end{array}$ & $\begin{array}{c}\text { Dip } \\
\text { angle }\left({ }^{\circ}\right)\end{array}$ & $\begin{array}{c}\text { Numerical } \\
(\mathrm{MPa})\end{array}$ & $\begin{array}{c}\text { Direction } \\
\left(^{\circ}\right)\end{array}$ & $\begin{array}{c}\text { Dip angle } \\
\left({ }^{\circ}\right)\end{array}$ \\
\hline 1 & 620 & 22.95 & 112.58 & 17.76 & & 19.11 & 10.68 & & 259.52 & 69.08 \\
\hline 2 & 620 & 29.45 & 102.65 & -13.4 & 18.05 & -10.15 & -10.34 & 15.53 & 116.32 & -72.9 \\
\hline 3 & 636 & 24.87 & 269.70 & -2.80 & 16.41 & 0.31 & -12.11 & 15.71 & 166.89 & 77.56 \\
\hline
\end{tabular}

$$
\left\{\begin{array}{l}
f^{(0)} \text { the initial value is arbitrary, } \\
f_{j}^{k+1}=f_{j}^{k}+\frac{\sum_{i=1}^{M}\left[d_{i j}\left(t_{i}-\left(d_{i}, f^{k}\right)\right) / \sum_{j=1}^{N} d_{i j}\right]}{\mu+\sum_{i=1}^{M} d_{i j}} .
\end{array}\right.
$$

In the formula $i=1,2, \ldots, M$ is the ray symbol, $j=1,2$, $\ldots, N$ is the unit number, $k=0,1, \ldots$, are the number of iterations.

When $\left\|f^{k+1}-f^{k}\right\|_{\infty}<\varepsilon$, take $\hat{f}=f^{k+1}$. Where is the allowable error of a given iteration?

Compared with the traditional BPT and ART methods, the SIRT algorithm has the advantages of good convergence, high resolution of reconstructed image, and low dependence on the accuracy of initial value selection. Most of the results are inversion results obtained by the SIRT method for geological interpretation of seismic wave CT images.

The detection range is $130 \mathrm{~m}$, from 5 to $135 \mathrm{~m}$ in front of the 311102 working face: the firing guns are arranged in the auxiliary transportation channel of the 311102 working face. There are a total of 27 guns, with a spacing of $5 \mathrm{~m}$, blasting hole depth of $2 \mathrm{~m}$, and charge of $100 \mathrm{~g}$ per hole. The receiving ends are arranged in the main canal groove, with a total of 11 (red short lines in Figure 5(c)), and the spacing is $13 \mathrm{~m}$. It is necessary to connect the signal line at $600 \mathrm{~m}$, and reserve a round-shift (i.e., 24 hours) stopping distance with the working face for the first blasting hole in construction, usually at $20 \mathrm{~m}$, to avoid the stopping of the hole. The specific layout of the detection system diagram is shown in Figure 5(c). On December 27, 2015, the stress field of coal pillars between the main transport and auxiliary transport channel of the 311102 working face was detected. The field design fired guns 27 times; 25 effective guns were received, of which the 4 th and 13 th guns were invalid. As we can see from Figure 5(c), the distribution of velocity lines at the excitation end and the receiving end. The denser the intersecting lines in the figure, the more accurate the effect of the velocity field. In the figure, because the linear density at both ends of detection is small, it is easy to cause boundary effect, so the analysis is omitted. Figure 5(b) shows the detection results of PASAT-M portable microseismic mode for the main and auxiliary coal pillars in the 02 working face. The horizontal axis is the main strike distance of the coal pillars, and the vertical axis is the width of the coal pillars.

As shown in Figure 5, the peak pillar stress is close to the working face (Red and Yellow), and pillar stress in 15-45 m zone is generally smaller than that of $15-45 \mathrm{~m}$ zone but greater than the other zones. The relatively higher pillar stress near the haulage gate indicates that the shifted symmetrical pillar stress distribution was clearly affected by mining activities on the 02 working face. In the $15-50 \mathrm{~m}$ zone, peak pillar stress is still at the pillar center, but the higher side stress is shifted to the main gate. Pillar stress in the $45-90 \mathrm{~m}$ zone presents a saddle shape distribution, where side-stress is relatively higher and inner-stress is relatively lower with an $8 \mathrm{~m}$ diameter zone. This phenomenon revealed the conservativity of the $30 \mathrm{~m}$ thick coal pillar design in Bayangaole mine and showed optimization opportunities. In a stress zone greater than $90 \mathrm{~m}$, much lowered pillar stress is presented in blue color, which proved that the advance stress range is smaller than $90 \mathrm{~m}$, and it matches with the borehole stressmeter readings.

\subsection{Observation of 3\# Coal Pillar Stress at the Location of the} Roadway. For the estimation of stress distribution behaviors, borehole stressmeters were applied to discover the local point stress, and form correlations with the sonic wave velocities that occur across entire coal pillar. In total, 9 borehole stressmeters were placed in the coal pillar between the 02 haulage gate and 03 ventilation gate with a drilling depth of $10 \mathrm{~m}$ and a drilling height of $1.5-1.8 \mathrm{~m}$. In consideration of pillar stress variation on the 02 working face, boreholes were designed with inconsistent distances along with the pillar wall between the 02 haulage gate and 03 ventilation gate as shown in Figure 6.

Stressmeters were installed simultaneously; the stress readings were recorded for each $30 \mathrm{~min}$ when the stress variation is greater than $0.5 \mathrm{MPa}$, and all the stress data were automatically saved from January to June in 2016. As the amount of recorded stress data is massive, minor stress variation and outliers, which were created by the relatively far distance from the working face and the instability of monitoring system, have been neglected and the mean stress was taken every day.

It can be seen from Figure 7 that the pillar stress increases first and drops suddenly overall along with the working face advancement. The tested pillar stress at monitoring point No.2 was increased and then dropped; this phenomenon matches with the previous testing result, and it proved that the roof was broken at $6 \mathrm{~m}$ from the working face which is in the small tectonic stress dropping zone.

According to the characteristics of pillar stress variation as shown in Figure 7, coal body along with the working face direction that are affected by excavation activities can be distinguished into 3 zones as shown below.

(1) Mildly Impacted zone is in the coal body which is more than $24 \mathrm{~m}$ ahead of the working face. In this zone, bearing pressure and country-rock pressurization are both minor, hence the coal body is barely affected by the excavation activities. 


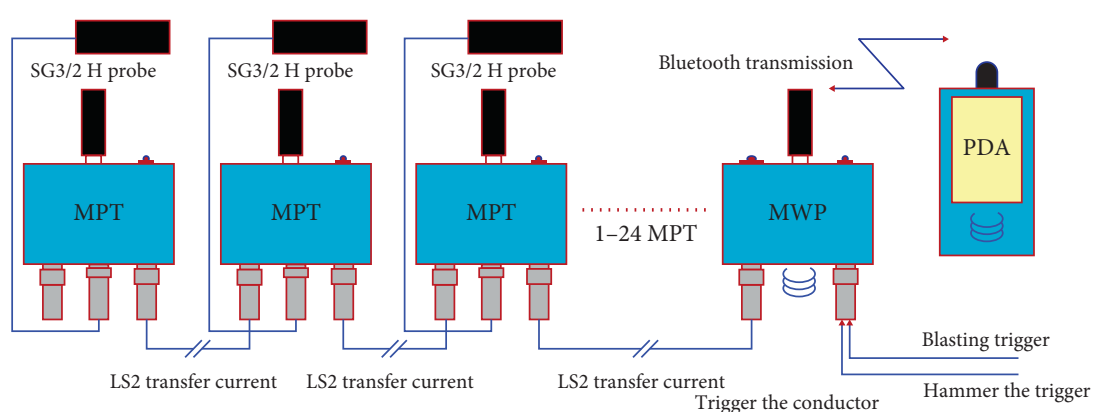

(a)

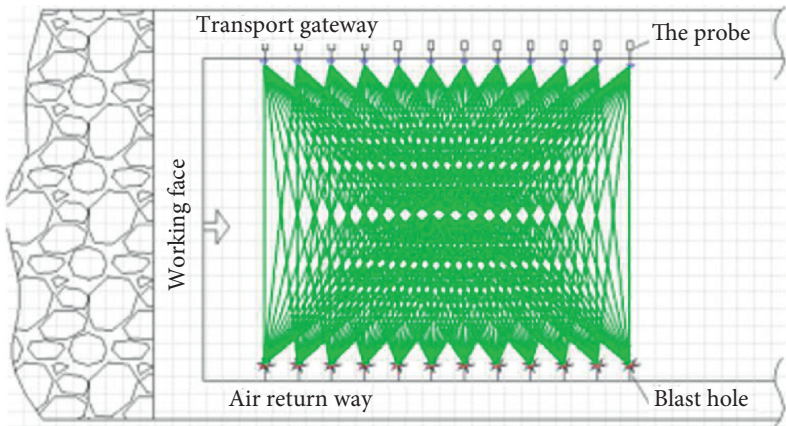

(b)

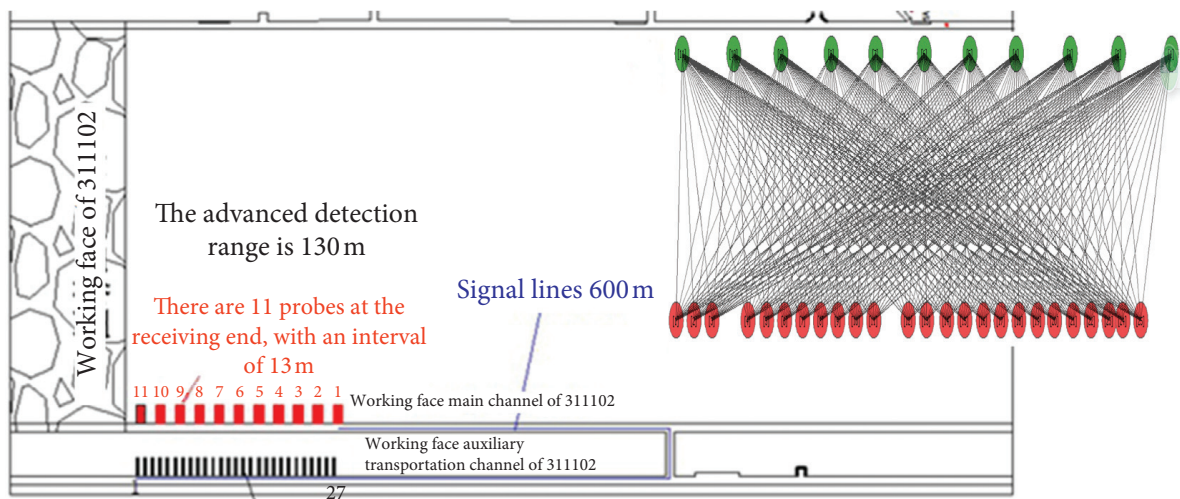

A total of 27 guns were fired at the fining end, with hole spacing of $5 \mathrm{~m}$, hole depth of $2 \mathrm{~m}$, and charge of $100 \mathrm{~g}$ per hole

(c)

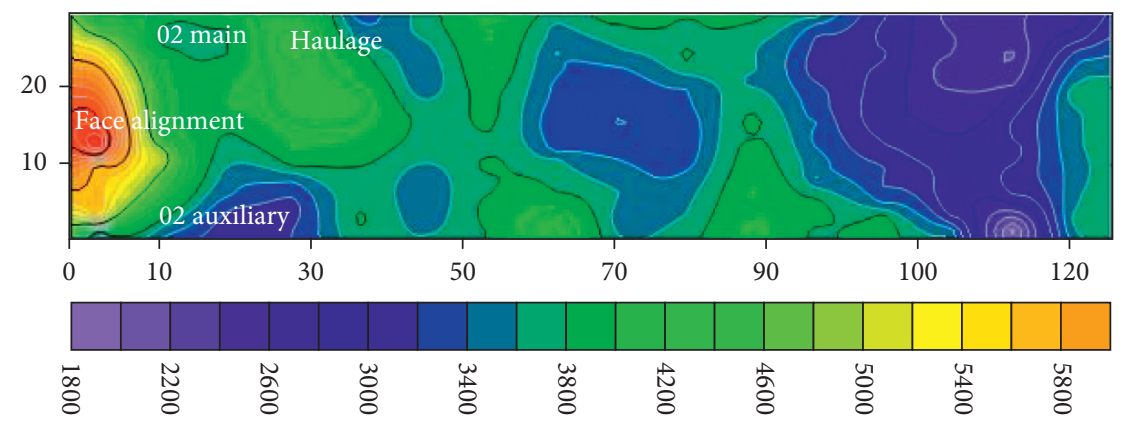

(d)

FIgURE 5: PASAT-MPortable microseismic detection system and coal pillar stress field. (a) Seismic CT technical schematic diagram of the coal mining face. (b) Seismic CT technical schematic diagram of the coal mining face. (c) 311102 working face pillar of the coal PASAT-M monitoring programme. (d) 311102 coal pillar wave velocity field between main transport and auxiliary transport on the working face. 


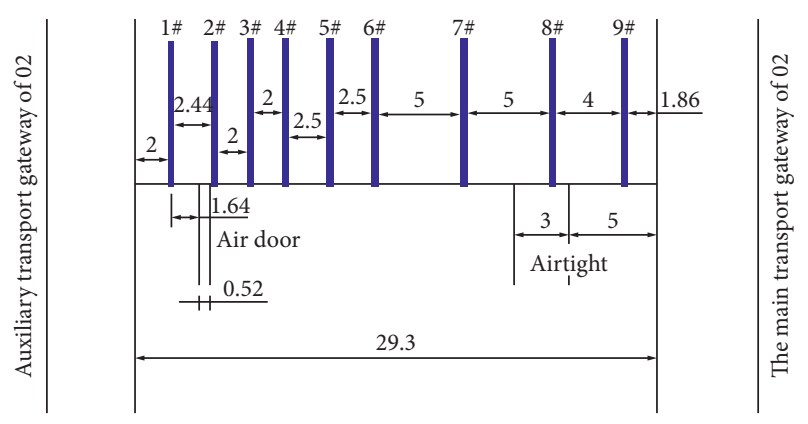

FIgURE 6: 3\# schematic diagram of borehole stressmeter layout in the roadway.

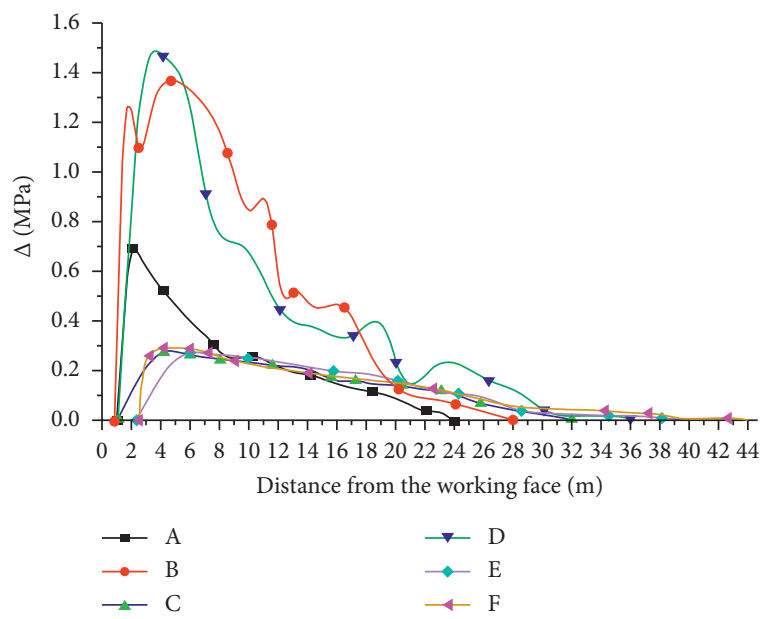

FIGURE 7: The variation of stress with distance at different measuring points $(\Delta \mathrm{P}-\mathrm{L})$ graph. A: $2 \mathrm{~m}, \mathrm{~B}: 4.44 \mathrm{~m}, \mathrm{C}: 6.44 \mathrm{~m}, \mathrm{D}: 8.44 \mathrm{~m}$, E: $10.94 \mathrm{~m}$, and F: $13.44 \mathrm{~m}$.

(2) Ordinarily Impacted zone is in the coal body which is between 8 and $24 \mathrm{~m}$ ahead of the working face. In this zone, the increment of bearing pressure and the corresponding country-rock deformation are more intensive compared with the mildly impacted zone.

(3) Severely Impacted zone is in the coal body which is less than $8 \mathrm{~m}$ ahead of the working face. In this zone, the excavation caused a significant bearing pressure increment, where the maximum bearing pressure is located around $5 \mathrm{~m}$ ahead of the working face, whereas the bearing pressure at the working face is much smaller.

It can be seen from Figure 8 that the stress is high at the measuring point $1 \#(2 \mathrm{~m})$, low at the measuring points $2 \#$ and $3 \#$ (4.44 $\mathrm{m}$ and $6.44 \#)$, rising at the measuring points $4 \#$ and 5\#, peak at the measuring point 6\# (13.44), and then decreases. According to the above results, the coal pillar stress is maximum at $13.44 \mathrm{~m}$, which is consistent with the simulation result that the coal pillar stress is superimposed at $15 \mathrm{~m}$. At $4.44 \mathrm{~m}$ and $6.44 \mathrm{~m}$, the stress is low, indicating a small structure.

Therefore, the initial excavation has a relatively low impact on coal pillar, and a bimodal shape relationship was discovered based on the stress distribution curve.
When the working face is within $13.94 \mathrm{~m}$ from the ventilation gate, coal pillar was greatly impacted, and the pillar stress distribution showed a similar bimodal correlation with both peak stresses at 2 and $8 \mathrm{~m}$ from the coal rib. The stress crest appeared in-between 4 and $6 \mathrm{~m}$.

By referring to the previous loose circle test results, the loss circle diameter of the doubly impacted pillar is determined as $3.6 \mathrm{~m}$. In consideration of water proofing and ventilation efficiency, this long wall mining excavation is design with a $4-6 \mathrm{~m}$ coal pillar thickness, tunnel centerline at $8 \mathrm{~m}$, and a roadway width within $4 \mathrm{~m}$.

\section{Research on Reasonable Theoretical Width of Coal Pillar Retention}

Strip coal pillar not only isolates stopping roadway from goaf but also maintains roadway stability. As the coal pillar is the main body that supports the roadway, its deformation and failure behaviors have a great influence on the controlling of roof strata. Based on the research, the extent of the influence that coal pillar geometry has created on the stopping roadway failure behaviors is one of the main factor relating to the stability of stopping road way country-rock. Therefore, reasonable coal pillar geometry can not only reduce both roadway deformation and maintaining workload but also improve the recovery rate compared with the overly designed pillar geometry.

The traditional section pillar design leaves the coal pillar to support the roof between upper haulage drift and lower ventilation drift; hence, it allows the drifts in lower panels to avoid the peak abutment pressure zone. It is true that twoway advancing method in section drifts is beneficial for technical management, ventilation, transportation, drainage, and mining safety. However, the loss of coal pillar is as high as $10 \% \sim 30 \%$, and the return air roadway is affected by secondary mining. Therefore, the maintenance of roadway is difficult, and the support cost is high. Not only this, the abandonment pressure that spreads to the floor through coal pillar can not only affect both surrounding excavation and floor stability but also produce risks on inducing rock burst.

The most common failure modes, when the coal pillar stress and deformation reach its ultimate bearing capacity of deformation limit, are shear failure, splitting failure, rheodestruction failure, sliding failure along with weak plane and bedding, and heaving failure when coal pillar is punched into the floor.

Coal pillar width is the major factor that affects its stability and roadway maintenance. The width of coal pillar determines the horizontal distance between roadway and mining space and affects the influence degree of abutment pressure caused by mining on roadway and the load of coal pillar. Therefore, coal pillar's ultimate bearing capacity not only depends on its boundary conditions and mechanical properties but also relies on its geometry.

Goaf in the upper panel is on one side of the strip coal pillar, whereas the preparation roadway in the lower panel is on another side. Plastic deformation zones are formed by both upper goaf and preparation roadway on both pillar sides with plastic zone widths of $x_{0}$ and $x_{2}$, respectively, as 


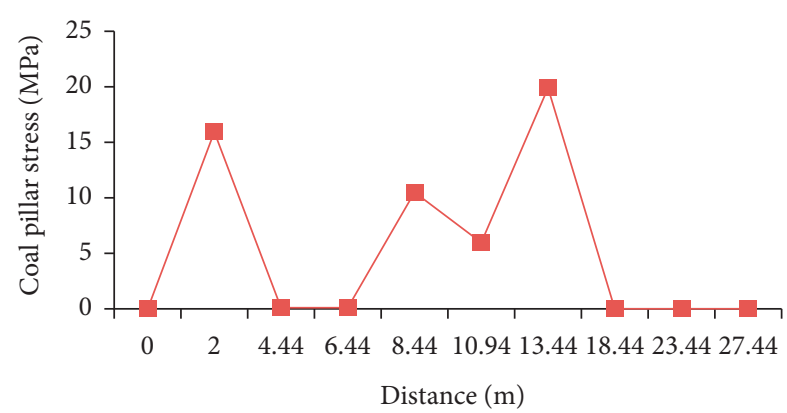

FIGURE 8: Internal stress curve of coal pillar.

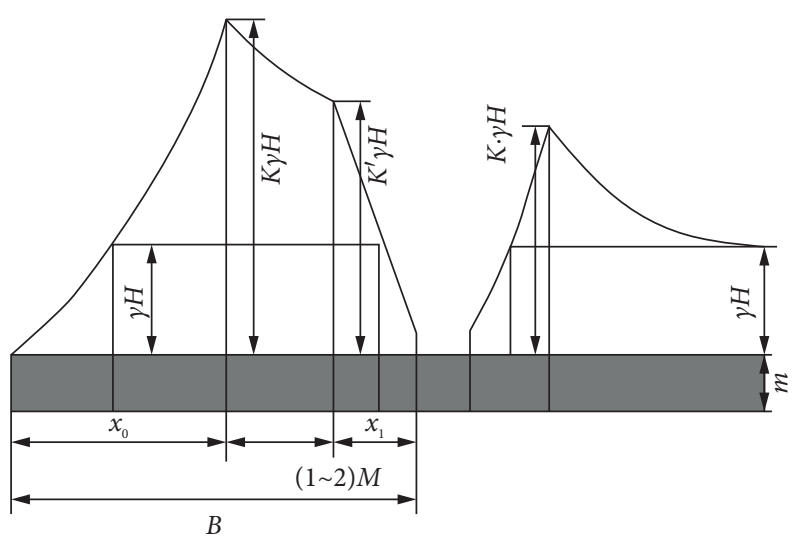

FIGURE 9: Elastic-plastic deformation zone and stress distribution of coal pillar.

shown in Figure 9. Therefore, the basic conditions for the stability of the coal pillar for roadway protection are as follows: after plastic deformation occurs on both sides of the coal pillar, there is an elastic core of a certain width in the center of the coal pillar, and the width of the elastic core should not be less than 2 times of the height of the coal pillar. On the contrary, when the elastic core width is smaller than 2 times the pillar height such as excavating a very narrow roadway in coal pillar, the redistributed pillar stress will reduce the effective bearing area and finally result in a dramatic drop in the pillar bearing capacity.

There are two ways to avoid stress concentration based on the fact that peak rib bearing stress is located inside of the coal pillar as shown in Figure 10. One approach is that the coal pillar must have a sufficient width; hence, the stress concentration cannot be released easily since it is confined by relatively thick coal body. Another approach is that the coal pillar must be small enough; hence, the peak stress will not fall into the coal pillar.

The alignment of Bayangaole mine 311102 large height working face is designed along with the 3-1 coal seam floor. After the face excavation started, the redistributed countryrock in-situ stress first caused rib coal failure, and then this failure expanded and shifted to the boundary of the elastic zone. Rock parting caused a lower cohesion $C_{0}$ and internal friction angle $\phi_{0}$ when compared with that of pure coal mass; the controlling object is focused on the upper coal body over the large roadway height.
A substantial amount of research outputs proved that the redistribution of bearing stress in country-rock is caused by the movement in overlaying strata and the behaviors of bearing stress distribution is mainly depending on the mechanical properties of coal mass and the overlaying strata movement. It is somehow similar to,

$$
\begin{aligned}
\sigma_{y} & =\frac{C_{0}}{\tan \phi_{0}} e^{\left(2 \tan \phi_{0} / M \lambda\right) x}-\frac{C_{0}}{\tan \phi_{0}}, \\
R_{0} & =\frac{M \lambda}{2 \tan \phi_{0}} \ln \left[\frac{K \gamma H+\left(C_{0} / \tan \phi_{0}\right)}{C_{0} / \tan \phi_{0}}\right] .
\end{aligned}
$$

In the formula: $\lambda$-Coefficient of lateral pressure. The formula $\lambda=\mu(1-\mu)$ can get $\lambda=0.75, K$-Coefficient of stress concentration due to stopping, take $3 ; \gamma$-The average bulk weight of the overlying strata, take $2.5 \mathrm{t} / \mathrm{m}^{3} ; \mathrm{H}$-Mining depth, take $610 \mathrm{~m} ; M$-One-off mining thickness of coal seam, take $5.4 \mathrm{~m} ; C_{0}$-The cohesive force of the interface such as the bedding plane of the coal and rock mass itself, from the laboratory test results, take $8 \mathrm{MPa} ; \phi_{0}$-The internal friction angle of the interface such as the bedding plane of the coal and rock itself, from the laboratory test results, take $27^{\circ}$. Plug the data into the formula, calculated $R_{0}=4.96 \mathrm{~m}$.

Therefore, the theatrical plastic zone width of the section pillar (ultimate stress equilibrium width) in Bayangaole mine is determined as $4.96 \mathrm{~m}$. If the small pillar mining approach is adopted, the peak stress zone can be effectively avoided, hence its stability is ensured. This theatrical estimation verifies the stress monitoring results from Section 3. For further verifications, numerical simulation analysis was adopted to investigate the pillar stability.

\section{Numerical Simulation of Coal Pillars with Different Widths}

5.1. Simulation Scheme. FLAC3D model was established based on the geological features collaborated from 01, 02, 03 working faces, the $11^{\text {th }}$ panel zone, Bayangaole mine. And, the small pillar excavation was simulated at 03 working face with trial pillar widths of 5, 8, 10, 12, and $15 \mathrm{~m}$. By simulating the stopping activities of 02 and 03 working faces, the reasonable strip coal pillar width was determined based on pillar stress distribution, overlaying strata deformation, and failure behaviors.

The FLAC3D model contains 19314 elements, 208050 nodes, and it has a geometry of 645-655 m (length) $* 360 \mathrm{~m}$ (width) $* 74 \mathrm{~m}$ (height) with a $50 \mathrm{~m}$ extended outer boundary. The trial coal pillar widths are $3,5,8,10,12,15$, 20,25 , and $30 \mathrm{~m}$. As shown in Figure 11, by simulating the stopping activities of 02 and 03 working faces, the reasonable strip coal pillar width was determined based on pillar stress distribution, overlaying strata deformation, and its failure behavior.

Vertical stress $V$ at $620 \mathrm{~m}=15.74 \mathrm{MPa}$. Considering that the height of the whole model is $70 \mathrm{~m}$, the overburden of the coal seam is $38 \mathrm{~m}$, and the thickness of the coal seam is $5 \mathrm{~m}$, the stress test point is generally in the middle of the coal seam. Therefore, a load of $14.7 \mathrm{MPa}$ is applied vertically to 


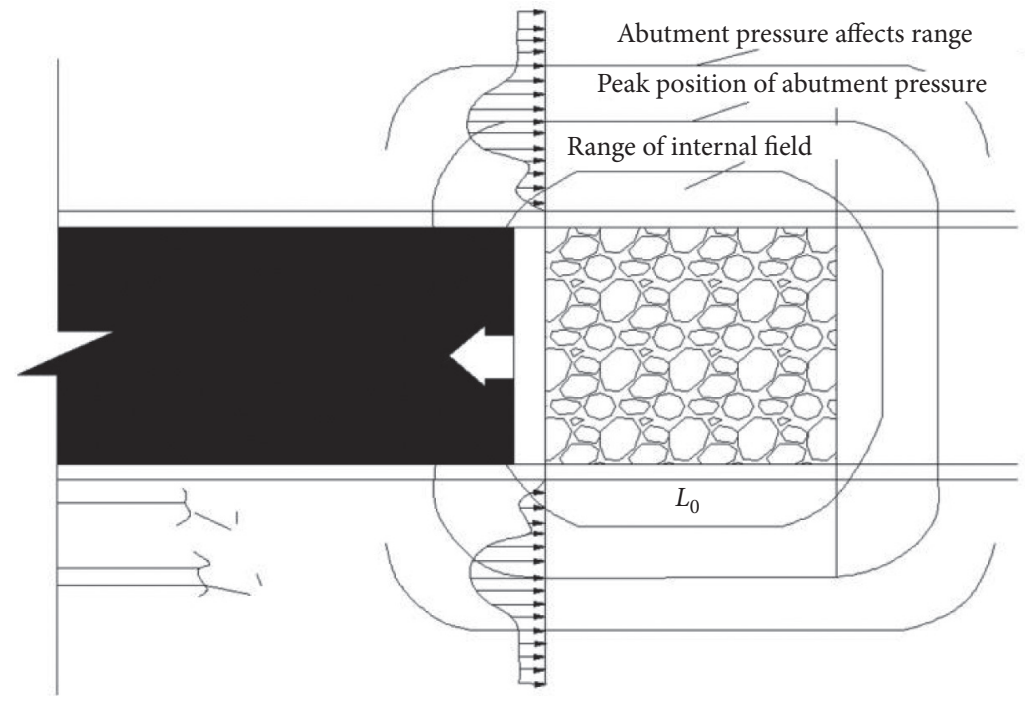

FIGURE 10: Schematic diagram of mining stress.

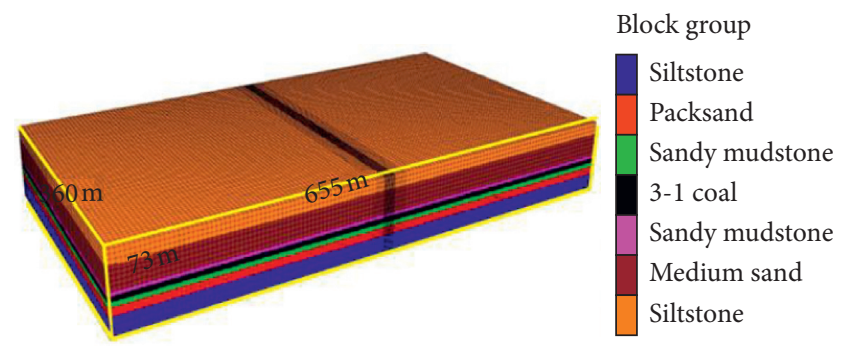

FIGURE 11: FLAC3D model.

the upper part of the model, which represents the weight of the upper part of the rock mass. The boundary conditions of the model include displacement boundary and stress boundary, where the boundary conditions of the model are set as follows: the left and right boundaries only constrain the displacement in the $X$ direction, and the front and rear boundaries only constrain the displacement in the $Y$ direction, that is, the single constraint boundary. The lower boundary is a fully constrained boundary, and the upper boundary is unconstrained. The Mohr-Coulomb yield criterion is used in the failure criterion of coal and rock mass.

Fissure structures, including joints, have great influences on rock mass physical-mechanical parameters, and it consequently affects the results of numerical simulation. Therefore, rock mass properties were optimized based on the intact rock parameters obtained from the laboratory test, and the corresponding rock mass parameters are all listed in Table 4.

5.2. The Stress Variation Rule of Coal Pillar with Different Widths during Stopping of Working Face. As the strip coal pillar is located between 02 and 03 working face, influences created by mining actives are doubly accumulated. The entire simulation is started with 02 working face excavation, and the various trail coal pillar widths were set after the stress calculation is in the equilibrium state. And then, the stopping of the 03 working face was initiated, hence the coal pillar stress variation behaviors can be analyzed when stopping is simulated at both working faces. Figure 12 shows the stress distribution variations in coal body during the stopping in both 02 and 03 working faces.

As shown in Figure 12, the coal pillar width variation does not affect the stress distribution much during the 02 working face excavation. When coal pillar width increased from 3 to $30 \mathrm{~m}$, the corresponding peak vertical stresses are always inbetween 40 and $50 \mathrm{MPa}$, but the pillar stress distribution changed as the peak stress zone shifted to the 02 goaf zone.

In comparison, the coal pillar width variation has a relatively big influence on stress distribution at the 03 working face. The $3 \mathrm{~m}$ wide coal pillar was crushed, and its maximum stress concentration shifted to the roadway. Whereas, when coal pillar widths are $5,8,12,15,20,25$, and $30 \mathrm{~m}$, the corresponding maximum stress and stress concentration coefficients are $71 \mathrm{MPa}, 4.4 ; 82 \mathrm{MPa}, 5.1 ; 145 \mathrm{MPa}, 9 ; 116 \mathrm{MPa}$, 7.2; 89 MPa, 5.5; 73.6 MPa, 4.6; 69.3 $\mathrm{MPa}, 4.3$; and 66.8 $\mathrm{MPa}$, 4.1, respectively. An increasing trend is observed in the stress concentration factor when the pillar width increases from 5 to $10 \mathrm{~m}$. When coal pillar width increases from 10 to $12 \mathrm{~m}$, its concentration coefficient remains over 7 , and it poses extreme danger to roadway stability; On the contrary, the stress concentration coefficient drops when pillar width increases from 10 to $30 \mathrm{~m}$. Especially for coal pillar greater than $20 \mathrm{~m}$, its corresponding stress concentration remains below 5 , which is beneficial to the pillar stability.

It is found that when coal pillar thickness is $15 \mathrm{~m}$, the corresponding pillar stress is smaller than that of 10 and $12 \mathrm{~m}$ thick pillars, but still at a relatively high level. Therefore, the numerical simulation proved that pillar width between 5 and $8 \mathrm{~m}$ benefits its stability the most due to the relatively small corresponding peak vertical stress.

5.3. Stress Characteristics of Coal Pillar with Different Widths. The pillar stress characteristics were analyzed based on a representative scenario when the 03 working face is advanced by $130 \mathrm{~m}$, as well as the strip pillar is influenced by both 02 
TABLE 4: Table of physical and mechanical parameters of coal strata.

\begin{tabular}{|c|c|c|c|c|c|c|c|}
\hline Coal bed name & $\begin{array}{l}\text { Thick } \\
(\mathrm{m})\end{array}$ & $\begin{array}{l}\text { Bulk modulus } \\
(\mathrm{GPa})\end{array}$ & $\begin{array}{l}\text { Shear modulus } \\
(\mathrm{GPa})\end{array}$ & $\begin{array}{c}\text { Internal friction } \\
\left({ }^{\circ}\right)\end{array}$ & $\begin{array}{l}\text { Cohesion } \\
(\mathrm{MPa})\end{array}$ & $\begin{array}{c}\text { Tensile strength } \\
(\mathrm{MPa})\end{array}$ & $\begin{array}{c}\text { Apparent density } \\
\left(\mathrm{kg} / \mathrm{m}^{3}\right)\end{array}$ \\
\hline Siltstone & 13 & 6.03 & 5.30 & 28.08 & 10.6 & 2.07 & 2516 \\
\hline $\begin{array}{l}\text { Medium } \\
\text { sandstone }\end{array}$ & 22 & 22.6 & 19.1 & 37.08 & 6.20 & 2.48 & 2304 \\
\hline $\begin{array}{l}\text { Sandy } \\
\text { mudstone }\end{array}$ & 3 & 18.9 & 9.73 & 31.46 & 10.2 & 1.11 & 2503 \\
\hline Coal & 5 & 1.20 & 0.86 & 27 & 8.00 & 1.85 & 1400 \\
\hline $\begin{array}{l}\text { Sandy } \\
\text { mudstone }\end{array}$ & 4 & 18.9 & 9.73 & 31.46 & 10.2 & 1.11 & 2503 \\
\hline $\begin{array}{l}\text { Medium } \\
\text { sandstone }\end{array}$ & 8 & 2.73 & 2.31 & 32.54 & 8.00 & 1.17 & 2108 \\
\hline Siltstone & 18 & 6.03 & 5.30 & 28.08 & 10.6 & 2.07 & 2516 \\
\hline
\end{tabular}

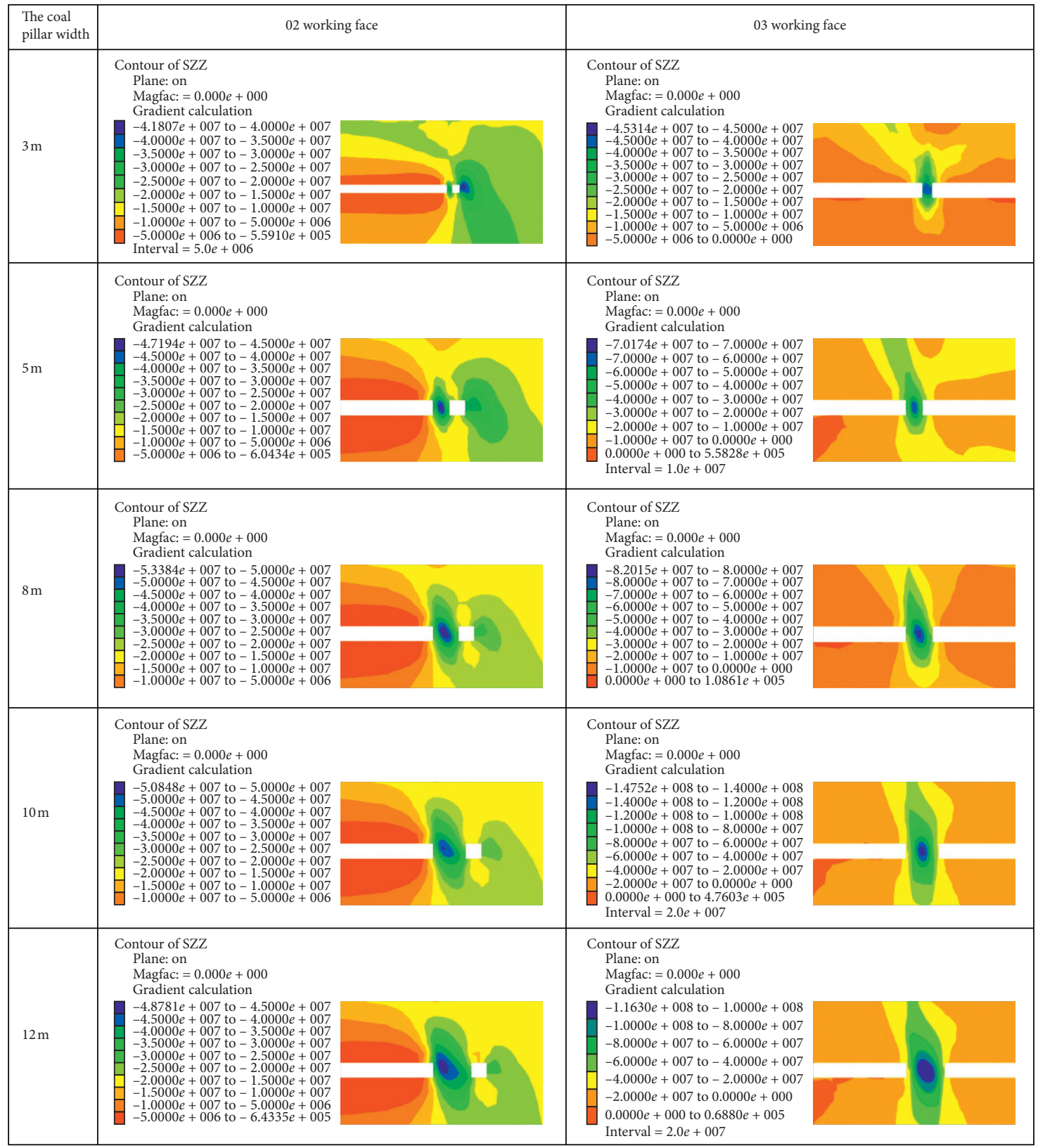

(a)

Figure 12: Continued. 


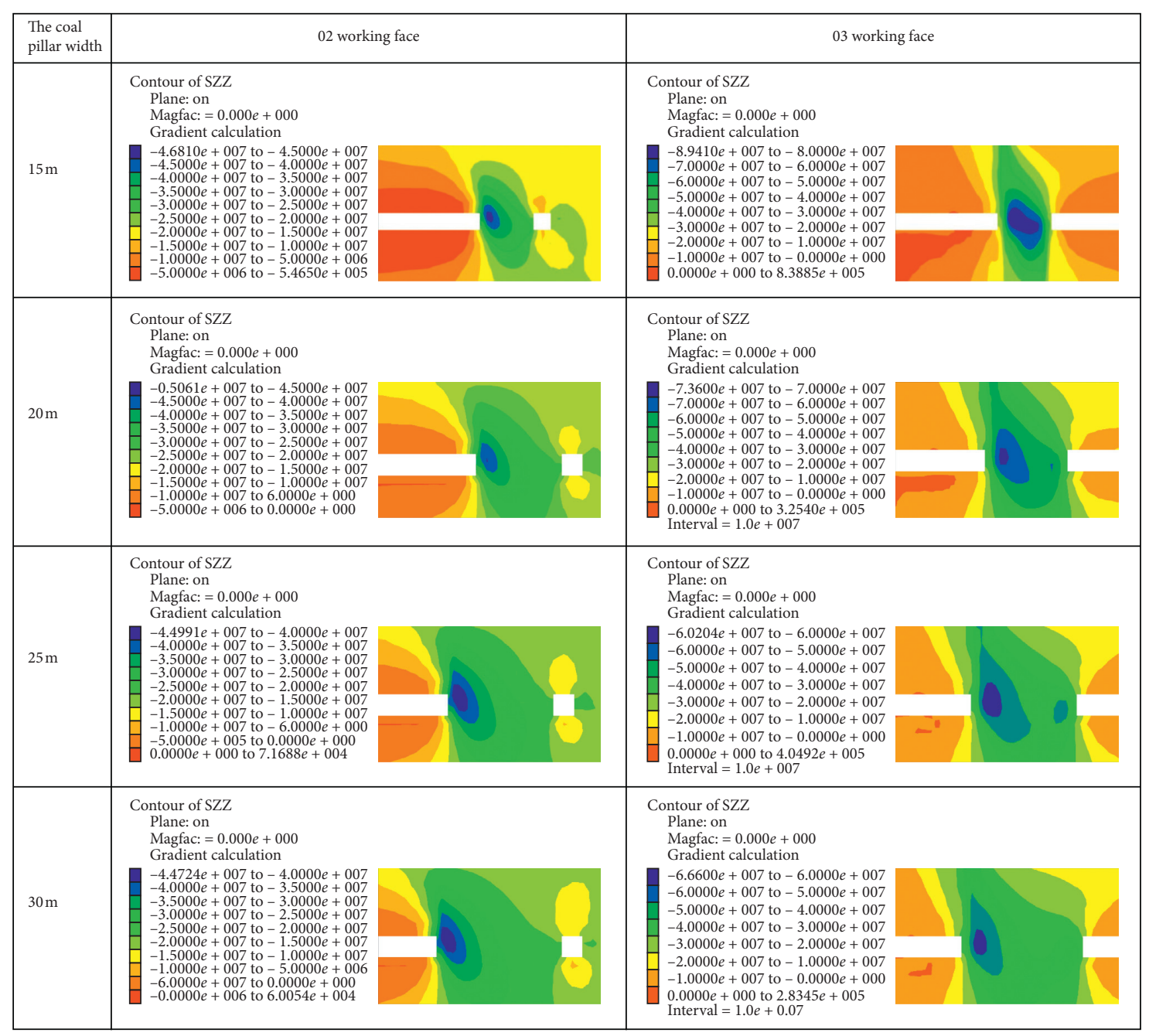

(b)

FIgURE 12: Vertical stress distribution diagram of coal pillars with different widths of $02 \#$ and $03 \#$ working faces during mining.

goaf and 03 working face excavations. The vertical stress vs pillar width curves are shown in Figure 13. It can be seen from Figure 13 that all the pillar stress distributions present a unimodal correlation and all peak stresses are shifted to the goaf side with a shifting range of $0.5-3 \mathrm{~m}$. Meanwhile, vertical stress is always the biggest and the difference in-between both horizontal stresses is barely noticed. However, the horizontal stress, which is parallel to the roadway alignment, is still slightly greater than that of perpendicular to the roadway alignment. When coal pillar width is in-between 3 and $5 \mathrm{~m}$, it was crushed and depressurized. When pillar width increases from 5 to $15 \mathrm{~m}$, both vertical stress and alignment-parallel horizontal stress are concentrated. When pillar width further increases from 20 to $25 \mathrm{~m}$, a bimodal correlation appeared and the peak stress close to the 02 working face is slightly higher than that of the 03 working face. It is also found that the stress at the pillar center is higher than the original rock stress, and the alignment-perpendicular horizontal stresses throughout the entire strip coal pillar are all smaller than the original rock stress.
5.4. Characteristics of Roadway Stress Field with Different Pillar Widths. The internal stress of the coal pillar is monitored by installing borehole stressmeter, and then the maximum stress in the coal pillar and solid coal of roadway side is extracted. The relationship between the characteristics of the roadway peak vertical stress and pillar width when the 03 working face was advanced by $130 \mathrm{~m}$ is shown in Figure 14. It can be seen from Figure 14 that the pillar width variation has certain influence on the vertical stresses in both coal pillar and coal rib. Figure 13 reveals that the curves of both peak vertical stress vs coal pillar width present a bimodal trend. With the increase of coal pillar width, the vertical pillar stress increases sharply and then drops mildly, whereas the lower coal rib stress slightly increases and then drops. Figure 14 also indicates that coal pillar bearing capacity is positively correlated to the pillar width, and the lower coal rib stress has a pillar-side shifting trend with the increases of pillar width. When coal pillar width reaches $8 \mathrm{~m}$, the upper rib coal pillar stress becomes much closer to that of lower coal rib, and until then all the lower coal rib stresses 


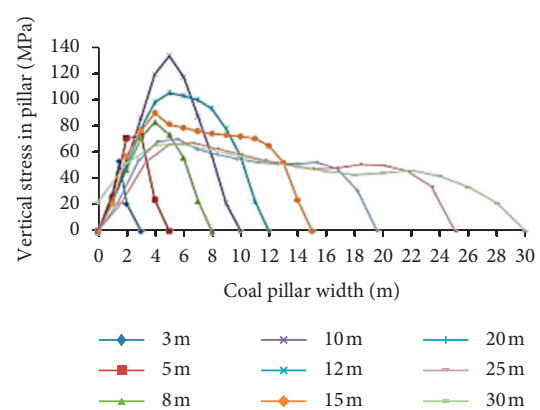

(a)

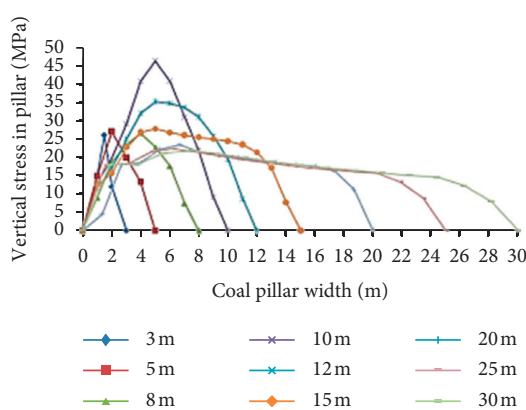

(b)

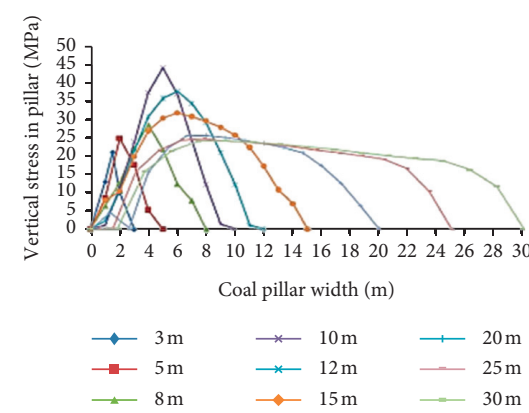

(c)

FIGURE 13: Stress distribution in coal pillar with different widths. (a) Vertical stress in pillar. (b) Horizontal stress in pillar (axial direction of parallel roadway). (c) Horizontal stress in pillar (vertical roadway axial direction).

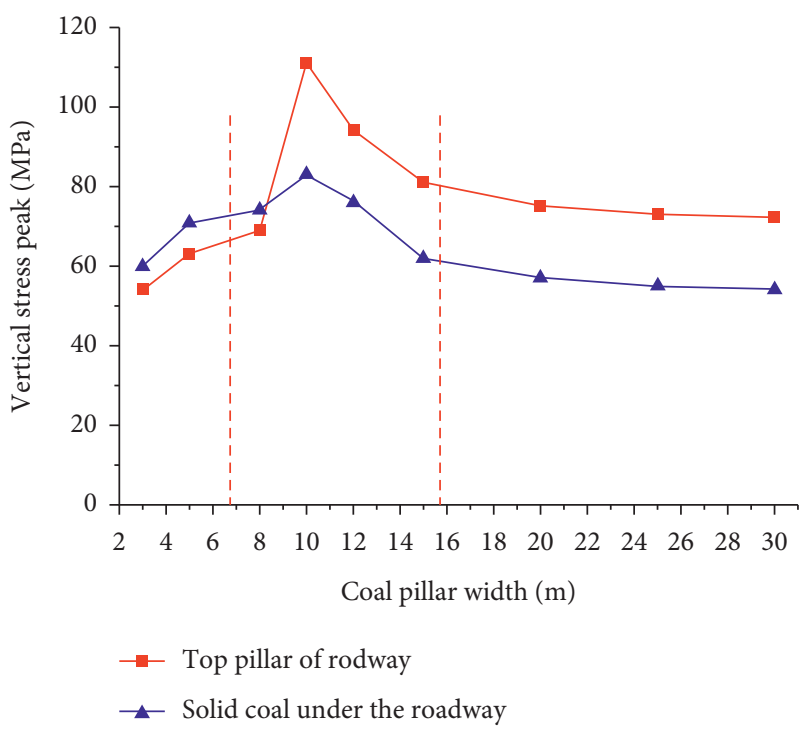

FIGURE 14: Stress distribution of roadway under different pillar widths.

are slightly greater than pillar stress. With a further increment in coal pillar (width $\geq 10 \mathrm{~m}$ ), the critical pillar stress remains much greater than that of lower coal rib stress, and it becomes the major load bearing object.

Overall, peak pillar stress and peak lower-rib stress appear together when the coal pillar is $10 \mathrm{~m}$ wide, and the difference in-between both upper and lower-rib peak stresses is minor due to the side supporting effect created by 02 goaf.

5.5. Characteristics of Roadway Displacement Field with Different Pillar Widths. The analyses of roadway countryrock deformation at $200 \mathrm{~m}$ ahead of the open-off cut focus on roof-floor convergence and rib-rib convenience. As shown in Figure 15, the accumulation of roof-floor convergence is inversely correlated to the working face distance, and it rapidly builds up when the working face approaches from $50 \mathrm{~m}$ away. The relationship between coal pillar width and relatively roof-floor displacement also presents a bimodal correlation. When coal pillar width increases from 5 to $10 \mathrm{~m}$, the relatively roof-floor displacement also increases and reaches its peak value. And then, it gradually drops when coal pillar width increases from 10 to $30 \mathrm{~m}$.

Regarding the rib-rib deformation, the results also reveal that its relative displacement is negatively correlated to the working face distance, and this trend intensifies further when the working face is within $40 \mathrm{~m}$.

Finally, based on the analyses of stress-displacement distributions in both coal pillar and coal rib, the strip pillar width is therefore recommended as $5-8 \mathrm{~m}$.

\section{Analysis of Stress Distribution of Coal Pillars with Different Widths When Excavating Goaf in the 03 Working Face}

6.1. Stress Variation Rule of Coal Pillar in Working Face with Widths of $5 \mathrm{~m}, 10 \mathrm{~m}$, and $15 \mathrm{~m}$. In order to see the stress distribution of the working face more comprehensively, when the coal pillar widths were $5 \mathrm{~m}, 10 \mathrm{~m}$, and $15 \mathrm{~m}$, the stress distribution diagrams were selected. In addition, when the working face of 03 was stopping at $130 \mathrm{~m}$, it can be seen from Figure 16 that the stress distribution forms of coal pillars in the mining area under three widths are different. The goaf formed by working face 02 will still affect the stress distribution of coal pillar to a certain extent. Under the influence of mining in working faces 02 and 03 , concentrated stress will be formed, and the maximum stress is located in a section behind the goaf. At the same time, under the action of advanced mining stress and lateral stress of the working face, the superposition of stress at the intersection of solid coal side and the pillar of the working face forms a high stress zone. With the decrease of the width of coal pillar, the stress concentration in the middle of coal pillar and the end of the working face on one side of coal pillar is increasing, and the distance between the stress concentration area and the roadway side is also getting closer.

6.2. Stress Characteristics of Coal Pillar with Different Widths. Figure 17 shows the stress characteristics of coal pillar when working face pushes $50 \mathrm{~m}$. As shown in Figure 17, the stress in $5 \mathrm{~m}$ and $10 \mathrm{~m}$ coal pillars presents a single peak distribution; the peak position is basically in the center of the coal pillar, and the vertical stress in $15 \mathrm{~m}$ coal pillar presents a bimodal distribution. The vertical stress in the coal pillar is 


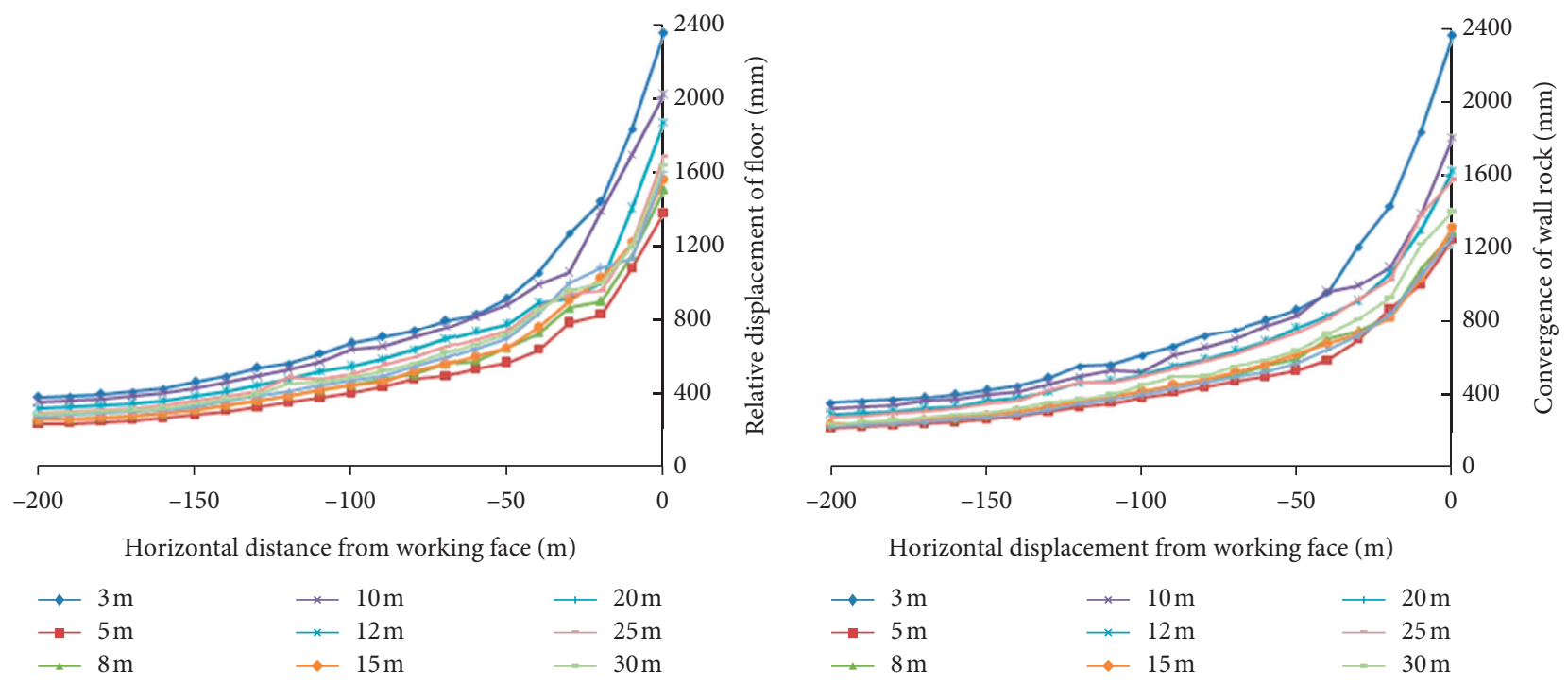

(a)

(b)

FIGURE 15: Relative displacement curve of roadway roof and floor at different pillar widths. (a) Vertical displacement curve. (b) Horizontal displacement curve of two sides.
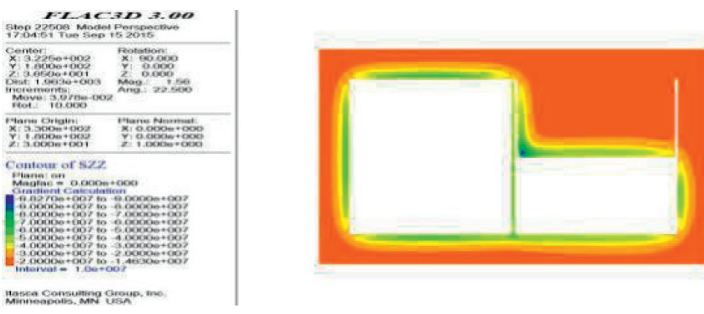

(a)

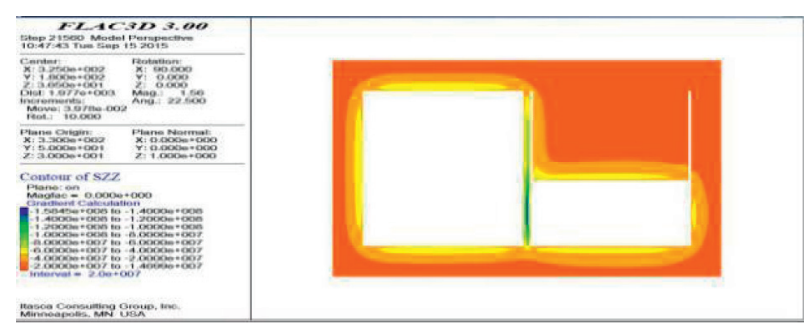

(b)
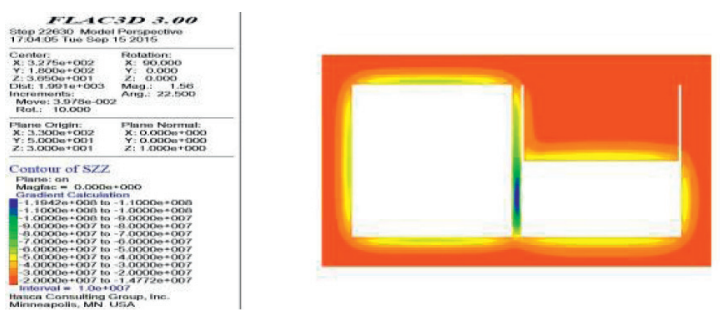

(c)

Figure 16: Stress nephogram at $130 \mathrm{~m}$ stope. (a) Width of pillar is $5 \mathrm{~m}$. (b) Width of pillar is $10 \mathrm{~m}$. (c) Width of pillar is $15 \mathrm{~m}$.

the largest, the difference between the two horizontal stresses is not big, but the overall horizontal stress parallel to the roadway axis is slightly larger than the horizontal stress perpendicular to the roadway axis. With the increase of the width of the pillar, the concentrated stress peak in the pillar first increases and then decreases, and the stress value is the largest in the pillar with a width of $10 \mathrm{~m}$.

6.3. Characteristics of Roadway Displacement Field with Different Pillar Widths. Fixed the position of $200 \mathrm{~m}$ in front of the 03 working face cut, and studied the top and bottom movement and convergence of the two sides in the mining When the mining distance reaches 200 meters in the front of the open-off cut, both the roof-floor's movement displacement and two sidewalls' movement displacement of different roadways for different coal pillar widths have been studied, respectively, in mining process. Figure 18 shows the relative vertical displacement curves of roadway roof and floor at different pillar widths, and Figure 19 shows the relative horizontal displacement curves of two sides of roadway at different pillar widths.

It can be seen from Figure 18 that with the decrease of distance from the working face, the moving amount of top and bottom increases and the trend accelerates. When the width of coal pillar increases from $5 \mathrm{~m}$ to $15 \mathrm{~m}$, the relative displacement of the roof and floor first increases and then decreases. When the width of coal pillar changes from $5 \mathrm{~m}$ to $10 \mathrm{~m}$, the relative displacement of roof and floor gradually 

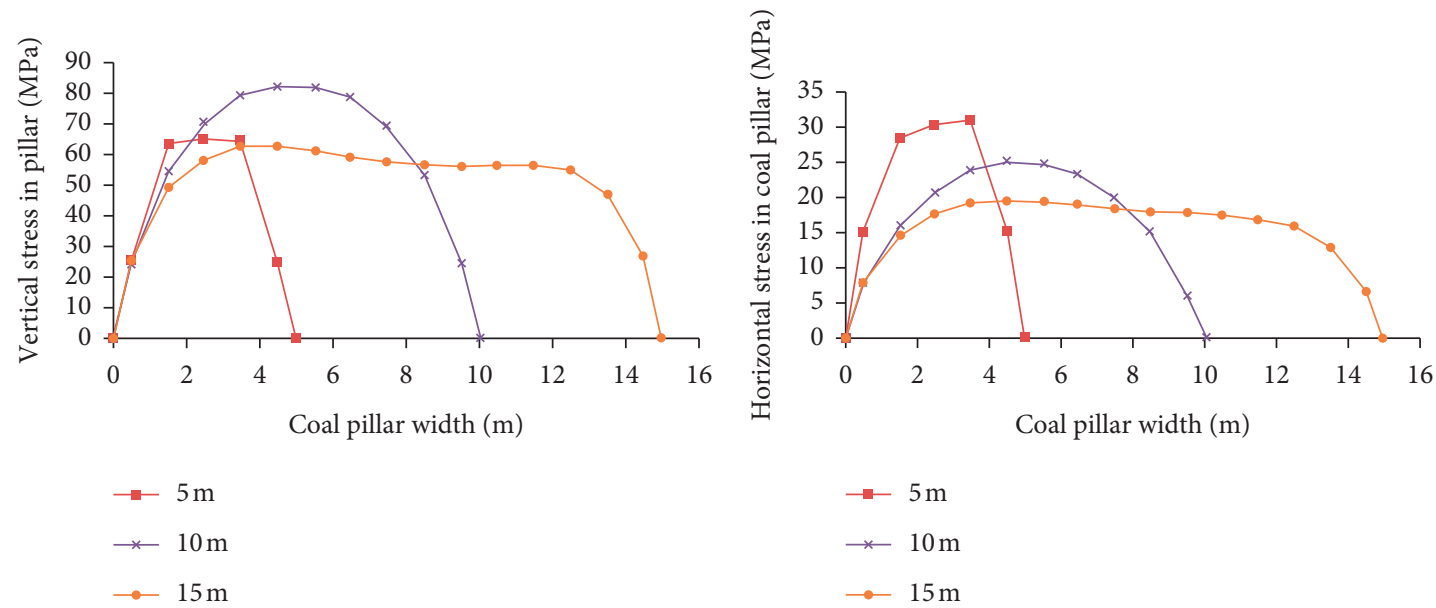

(a)

(b)

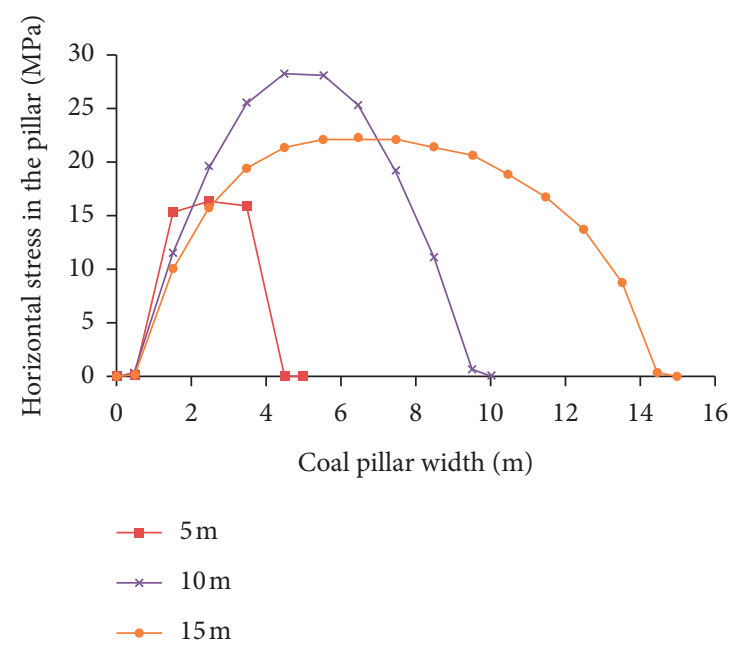

(c)

FIgURE 17: Stress distribution in coal pillar with different widths. (a) Vertical stress in pillar. (b) Horizontal stress in pillar (axial direction of parallel roadway). (c) Horizontal stress in pillar (vertical roadway axial direction).

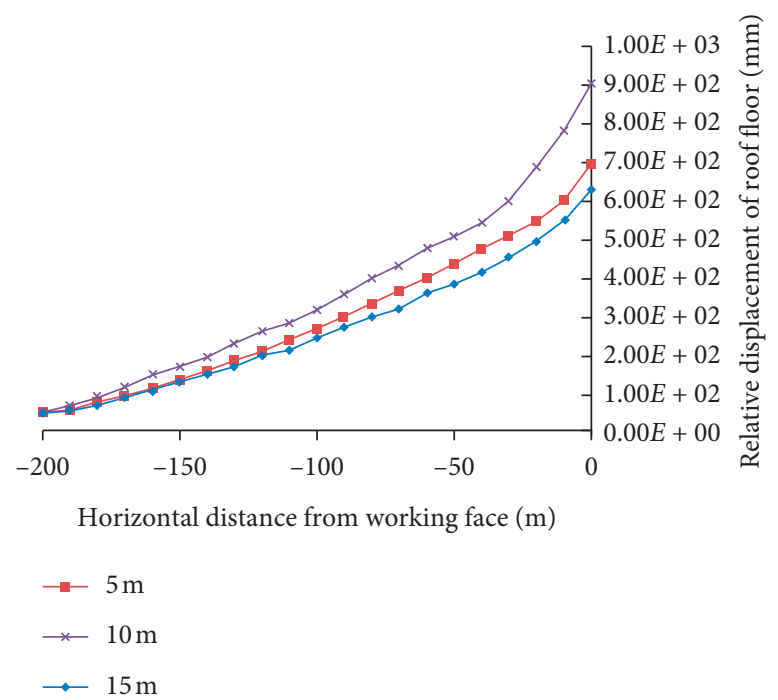

FIgURE 18: Relative vertical displacement curve of roadway roof and floor at different pillar widths. 


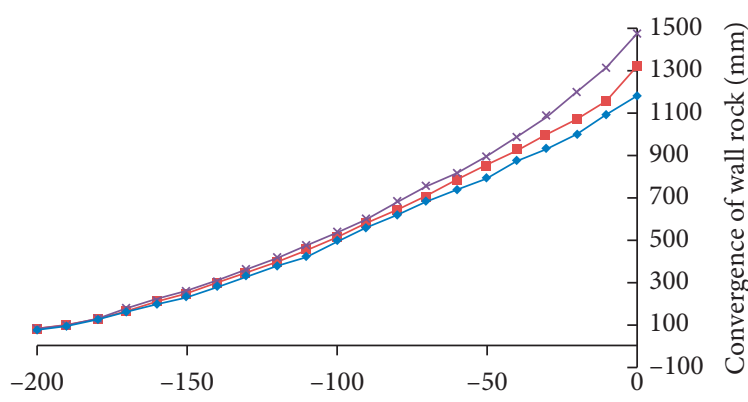

Horizontal distance from working face $(\mathrm{m})$

$\rightarrow-5 \mathrm{~m}$

$\rightarrow 10 \mathrm{~m}$

$\rightarrow 15 \mathrm{~m}$

Figure 19: Horizontal displacement curves of two sides of roadway at different pillar widths.

increases. When the width of coal pillar changes from $10 \mathrm{~m}$ to $15 \mathrm{~m}$, the displacement reaches the maximum.

As can be seen from Figure 19, along the strike, with the decrease of distance from the working face, the displacement value gradually increases and the curve is concave. When the width of coal pillar increases from $5 \mathrm{~m}$ to $10 \mathrm{~m}$, the relative horizontal displacement of two sides of the roadway increases. When the width of coal pillar increases from $10 \mathrm{~m}$ to $15 \mathrm{~m}$, the horizontal displacement of both sides of roadway decreases. However, the deformation of the roadway with a width of $5 \mathrm{~m}$ is slightly larger than that of the roadway with a width of $15 \mathrm{~m}$. Considering that the coal pillar with a width of $10 \mathrm{~m}$ can be mined, it is suggested that the reasonable width of the coal pillar at the side of goaf should be less than $10 \mathrm{~m}$. Combined with the previous field monitoring and referring to the small pillar retention situation of similar mines, the reasonable pillar width of BayanGaole coal mine is finally determined to be $6 \mathrm{~m}$. At present, the working face has been successfully stopped and produced obvious economic benefits.

\section{Conclusions}

Coal pillar width is the major factor that affects pillar stability and roadway maintenance. It dominates the horizontal distance between roadway and stopping space, and affects the bearing pressure under excavation and coal pillar bearing capacity. The coal pillar's ultimate bearing capacity not only depends on its boundary conditions and mechanical properties but also relies on its geometry. This paper revealed and analyzed the in-situ stress distribution of strip coal pillar in Bayangaole mine by utilizing rock mechanics testing, borehole stressmeter, PASSAT monitoring system, and numerical simulation. The small pillar excavation was practiced in Bayangaole mine and 5 essential conclusions are drawn.

(1) Based on the distribution patterns of acoustic wave velocity throughout coal pillar at the 311102 working face, it is discovered that the impact created by mining activity expands into the working face around $80 \mathrm{~m}$, where the peak stress concentration is found about $15 \mathrm{~m}$ ahead of the working face.

(2) Mildly Impacted, Ordinarily Impacted, and Severely Impacted zones are distinguished based on the borehole stressmeter testing results in Bayangaole mine. Mildly impacted zone is more than $24 \mathrm{~m}$ away from the working face. Ordinarily impacted zone is 8-24 $\mathrm{m}$ away from the working face, and the severely impacted zone is within $8 \mathrm{~m}$ from the working face. The peak coal body in-situ stress appears around $5 \mathrm{~m}$ ahead of the working face, whereas the in-situ stress is extremely low at the working face.

(3) The most common failure modes, when the coal pillar stress and deformation reach their ultimate bearing capacity of deformation limit are shear failure, splitting failure, rheodestruction failure, sliding failure along with weak plane and bedding, and heaving failure when coal pillar is punched into the floor. Based on the ultimate equilibrium theory, the plastic zone width of the 311102 working face coal body in Bayangaole mine is determined as $4.96 \mathrm{~m}$.

(4) The numerical simulation conducted both stress and displacement analyses on coal pillars with various widths. The results indicated that $5 \mathrm{~m}$ and $10 \mathrm{~m}$ wide pillars showed a unimodal stress-width correlation and the peak vertical stresses are all located at the pillar center, whereas $15 \mathrm{~m}$ wide pillar has a bimodal stress-width relationship. In comparison, $10 \mathrm{~m}$ wide pillar holds the maximum in-situ stress.

(5) In consideration of in-situ stress test results, sonic wave velocity test results, theatrical analysis, numerical simulation analysis, actual site conditions, and economic effects, $6 \mathrm{~m}$ wide pillar is designed at the working face 311102 . As a result, stopping was successfully completed and remarkable economic benefits were achieved.

\section{Data Availability}

The data are available upon request.

\section{Conflicts of Interest}

The authors declare that they have no conflicts of interest.

\section{Acknowledgments}

This study was financially supported by Beijing Excellent Young Scientists Project (BJJWZYJH01201911413037), the National Natural Science Foundation of China (41877257 and 51622404), and Key Project of Shaanxi Coal and Northern Shaanxi Mining Company (2018SMHKJ-A-J-03).

\section{References}

[1] D. Bunting, "Chamber pillars in deep anthracite mines," Transactions of the AIME, vol. 42, pp. 236-245, 1911. 
[2] F. L. Gaddy, "A study of the ultimate strength of coal as related to the absolute size of cubical specimens tested," Virginia Polytechnic Bulletin, vol. 112, pp. 1-27, 1956.

[3] A. Iannacchione and C. Mark, "Evaluating coal pillar mechanics through field measurements," in Proceedings of the 11th International Conference on Ground Control in Mining, pp. 38-47, WV, USA, July 1992.

[4] S. B. Giger, H. J. H. Ter, and B. Clennell, "Evolution of clay smears and associated changes to fault transmissibility using a new direct shear fluid cell," in Proceedings of the 2nd International Fault and Top Seals Conference, pp. 53-55, Montpellier, France, September 2009.

[5] M. D. G. Salamon, "Stability, instability and design of pillar workings," and Geomechanics Abstracts, vol. 7, no. 6, pp. 613-631, 1970.

[6] Y. Chen, J. Zuo, Z. Li, and R. Dou, "Experimental investigation on the crack propagation behaviors of sandstone under different loading and unloading conditions," International Journal of Rock Mechanics and Mining Sciences, vol. 130, Article ID 104310, 2020.

[7] J. P. Loui and P. R. Sheorey, "Estimation of non-effective width for different panel shapes in room and pillar extraction," International Journal of Rock Mechanics and Mining Sciences, vol. 39, no. 1, pp. 95-99, 2002.

[8] X. Li, M. Ju, and J. Shangkun, "Study on the influence factors and engineering application of the stability of narrow coal pillar along goaf," Journal of Mining and Safety Engineering, vol. 33, no. 5, pp. 761-769, 2016, in Chinese.

[9] J. Bai, C. Hou, and H. Huang, "Numerical simulation study on the stability of narrow coal pillar in gob roadway," Journal of Rock Mechanics and Engineering, vol. 23, no. 20, pp. 34753479, 2004, in Chinese.

[10] Y. Sun, J. Zuo, M. Karakus, and J. Wen, "A novel method for predicting movement and damage of overburden caused by shallow coal mining," Rock Mechanics and Rock Engineering, vol. 53, no. 4, pp. 1545-1563, 2020.

[11] X. Zeng, Z. Yao, and N. Zhang, "Stress distribution of coal pillar with gob - side entry driving in the process of excavation and mining," Journal of Mining and Safety Engineering, vol. 29, no. 4, pp. 459-465, 2012, in Chinese.

[12] K. Zhang, Y. Zhang, and Z. Ma, "The width of narrow pillar is determined along the goaf," Journal of Mining and Safety Engineering, vol. 32, no. 3, pp. 446-452, 2015, in Chinese.

[13] J. Zuo, J. Wang, and Y. Jiang, "Macro/meso failure behavior of surrounding rock in deep roadway and its control technology," International Journal of Coal Science \& Technology, vol. 6, no. 3, pp. 301-319, 2019.

[14] J. Wei, "The reasonable determination of the parameters of the coal house and coal pillar," Ground Pressure and Strata Control, pp. 106-108, 2003.

[15] W. He, F. He, and Y. Zhao, "Field and simulation study of the rational coal pillar width in extra-thick coal seams," Energy Science \& Engineering, vol. 8, no. 3, pp. 627-646, 2020.

[16] R. Frith and G. Reed, "Limitations and potential design risks when applying empirically derived coal pillar strength equations to real-life mine stability problems," International Journal of Mining Science and Technology, vol. 29, no. 1, pp. 17-25, 2019.

[17] Y Xue, Z. Cao, and Z. Li, "Destabilization mechanism and energy evolution of coal pillar in rockburst disaster," Arabian Journal of Geosciences, vol. 13, no. 12, pp. 287-306, 2020.

[18] J Li, "The plastic zone in surrounding rocks. Arabian Journal ofLi. The coal pillar design method for a deep mining roadway based on the shape of the plastic zone in surrounding rocks,"
Arabian Journal of Geosciences, vol. 13, no. 12, pp. 1005-1008, 2020.

[19] L. Shi, Y. Wang, M. Qiu, L Han, and Y. Zhao, "Research on the required width of a fault waterproof coal pillar based on underground pressure control theory," Arabian Journal of Geosciences, vol. 12, no. 15, pp. 1-14, 2019.

[20] S. Chen, X. Liu, Y. Zhu, and Z. Zhao, "Experimental study on progressive failure characteristics and mechanism of strip coal pillar," Journal of Mining \& Safety Engineering, vol. 36, no. 2, pp. 215-222, 2019.

[21] Y. Chen, J. Zuo, D. Liu, and Z. Wang, "Deformation failure characteristics of coal-rock combined body under uniaxial compression: experimental and numerical investigations," Bulletin of Engineering Geology and the Environment, vol. 78, no. 5, pp. 3449-3464, 2019.

[22] J. Zuo, Y. Chen, and C. Fan, "Analysis on the difference of mechanical properties and bursting liability of different coal and rock mass," Journal of China University of Mining \& Technology, vol. 47, no. 1, pp. 478-485, 2018, in Chinese.

[23] J. P. Zuo, X. Wei, Y. Shi, C. Liu, M. Li, and R. H. C. Wong, "Experimental study of the ultrasonic and mechanical properties of a naturally fractured limestone," International Journal of Rock Mechanics and Mining Sciences, vol. 125, pp. 1-12, Article ID 104162, 2020.

[24] H. Sun, X. L. Liu, S. G. Zhang, and K. Nawnit, "Experimental investigation of acoustic emission and infrared radiation thermography of dynamic fracturing process of hard-rock pillar in extremely steep and thick coal seams," Engineering Fracture Mechanics, vol. 226, Article ID 106845, 2020.

[25] J. Zuo, Z. Li, S. Zhao, Y. Jiang, H. Liu, and M. Yao, "A study of fractal deep-hole blasting and its induced stress behavior of hard roof strata in Bayangaole coal mine, China," Advances in Civil Engineering, Special: Dynamic Failure Characteristics and Behavior of Rock Materials, vol. 2019, Article ID 9504101, 14 pages, 2019.

[26] X. Liu, G. Han, E. Wang, S. Wang, and K. Nawnit, "Multiscale hierarchical analysis of rock mass and prediction of its mechanical and hydraulic properties," Journal of Rock Mechanics and Geotechnical Engineering, vol. 10, no. 4, pp. 694-702, 2018.

[27] W. Yu, G. Wu, B. Pan, Q. Wu, and Z. Liao, "Experimental investigation of the mechanical properties of sandstone-coalbolt specimens with different angles under conventional triaxial compression," International Journal of Geomechanics, vol. 21, no. 6, Article ID 04021067, 2021.

[28] G. Wu, W. Yu, J. Zuo, and S. Du, "Experimental and theoretical investigation on mechanisms performance of the rockcoal-bolt (RCB) composite system," International Journal of Mining Science and Technology, vol. 30, no. 6, pp. 759-768, 2020. 